\title{
Open Lake Phosphorus Forcing of Cladophora Growth: Modeling the Dual Challenge in Great Lakes Trophic State Management
}

\author{
Xing Zhou ${ }^{1}$, Martin T. Auer ${ }^{1}$ and Pengfei Xue ${ }^{1,2,3, * \mathbb{D}}$ \\ 1 Department of Civil, Environmental, and Geospatial Engineering and Great Lakes Research Center, \\ Michigan Technological University, Houghton, MI 49931, USA; xingzhou@mtu.edu (X.Z.); \\ mtauer@mtu.edu (M.T.A.) \\ 2 Environmental Science Division, Argonne National Laboratory, Lemont, IL 60439, USA \\ 3 Department of Civil and Environmental Engineering, Massachusetts Institute of Technology, \\ Cambridge, MA 02139, USA \\ * Correspondence: pexue@mtu.edu; Tel.: +1-906-487-1837
}

Citation: Zhou, X.; Auer, M.T.; Xue, P. Open Lake Phosphorus Forcing of Cladophora Growth: Modeling the Dual Challenge in Great Lakes Trophic State Management. Water 2021, 13, 2680. https://doi.org/10.3390/w13192680

Academic Editor: Reinaldo Luiz Bozelli

Received: 20 August 2021

Accepted: 22 September 2021

Published: 28 September 2021

Publisher's Note: MDPI stays neutral with regard to jurisdictional claims in published maps and institutional affiliations.

Copyright: (c) 2021 by the authors. Licensee MDPI, Basel, Switzerland. This article is an open access article distributed under the terms and conditions of the Creative Commons Attribution (CC BY) license (https:// creativecommons.org/licenses/by/ $4.0 /)$.

\begin{abstract}
Stimulated by excess levels of phosphorus, the attached, filamentous green alga Cladophora grows to nuisance proportions in Lake Michigan, one of the Laurentian Great Lakes. While nearshore waters impacted by local sources of the nutrient continue to support nuisance conditions, offshore waters have undergone oligotrophication in response to reductions in phosphorus loading and benthification of phosphorus cycling by invasive dreissenid mussels. A concept termed the Dual Challenge recognizes that implementation of more stringent phosphorus-loading objectives (to control Cladophora in the nearshore) stands in conflict with a foreseen need to mitigate oligotrophication in the offshore (to sustain a healthy fishery). Attention to this nearshore-offshore dynamic calls into play the role of cross-margin phosphorus transport in mediating both endmembers of the conflict. We applied a biophysical model simulating soluble reactive (SRP) and particulate (PP) phosphorus, mussel biokinetics, and cross-margin mass transport in addressing the Dual Challenge. Pre- and post-dreissenid monitoring results suggest that a reduction in offshore PP levels (food web nutrition) in excess of $40 \%$ (2.4 to $1.4 \mathrm{mgP} \cdot \mathrm{m}^{-3}$ ) has driven oligotrophication and attendant food web dysfunction. Yet, in the absence of local sources, model-predicted nearshore SRP levels remain at or below those required to prevent nuisance growth. These findings indicate that there is a margin of $\sim 1 \mathrm{mgP} \cdot \mathrm{m}^{-3}$ over which offshore PP levels could be increased (to the benefit of the food web and the fishery) without hindering efforts to reduce nuisance algal growth through local source control.
\end{abstract}

Keywords: Cladophora; phosphorus; dreissenid mussels; cross margin transport; Great Lakes; oligotrophication; dual challenge

\section{Introduction}

Cladophora glomerata, a filamentous green alga, colonizes solid substrate in four of the five Laurentian Great Lakes (Erie, Huron, Michigan and Ontario). Cladophora is considered to be an ephemeral macroalga as its growth is mediated seasonally by conditions of light and temperature. Biomass accrual is initiated in spring (May) and continues until a peak biomass is reached in mid-summer (July). At this point, the alga enters a period of late summer senescence (August), which continues into fall [1,2]. Nuisance growth of Cladophora has plagued the nearshore area of the Great Lakes for over 80 years [3], depositing mats of detached algal debris that fouls beaches, clogs water intakes, and harbors microbes that pose threats to wildlife (hosting avian botulism; [4]) and the public health (hosting bacterial pathogens; [5]).

When (seasonally) and where (depth and bottom type) the alga's requirements relating to light, temperature, and substrate for attachment are met, growth is limited by phosphorus (P; taken up in its soluble reactive form, SRP; [6,7]). Historically, nuisance 
conditions have tracked increases in population pressure and associated phosphorus discharges, becoming widespread across the four lower Great Lakes in the 1960s and 1970s [1]. With the implementation of point-source P management in the 1970s, the frequency of nuisance growth reports declined only to increase significantly with the invasion and proliferation of invasive mussels in the 1990s [3].

Ecosystem engineering by invasive dreissenid mussels (zebra mussels, Dreissena polymorpha, and quagga mussels, Dreissena rostriformis bugensis) have profoundly impacted conditions supporting Cladophora growth. As described by Hecky et al. [8], mussel filtration of particulate matter has increased water-column transparency (extending the colonizable depth for the alga), provided a particulate phosphorus (PP) to SRP shunt through mineralization of terrigenous and phytoplankton PP, and, by their simple presence, increased the surface area of hard substrate available for colonization. Kuczynski et al. [3], noting that the stored P content in and biomass accrual by Cladophora have both declined in Lake Ontario in the post-dreissenid period, concluded that clearing of the water column by mussel filtration and attendant expansion of colonization by the alga haves been the primary drivers for the resurgence of nuisance growth.

However, while habitat expansion has been identified as the fundamental cause of the resurgence, phosphorus continues to play a critical role. Of interest here is the dichotomy of whole-lake versus locally-forced nutrient supply, a condition particularly well illustrated by Lake Ontario. In the interval prior to the implementation of $P$ management, nuisance growth of Cladophora was widespread, occurring wherever light penetrated to the lake bottom and solid substrate for attachment were available; the system was whole-lake forced, supported by offshore P levels. Following implementation of P management, offshore levels of the nutrient fell precipitously [9], the nutritional status and rate of biomass accrual in Cladophora declined [10], and occurrences of nuisance growth became limited to sites locally impacted by phosphorus discharges [7].

While a strong case has been made for mussel-mediated water-column clearing as the driving force for resurgence, control of phosphorus loading has been recognized as the "primary, and perhaps only, remedial action that may address nuisance Cladophora growth" [11] (p. 7). It has been recommended that nearshore phosphorus management in the post-dreissenid era focus on local source control while ensuring that lake-wide levels do not increase [7]. Remediation of local sources may require increased regulation of nonpoint $\mathrm{P}$ sources and more stringent controls on point sources [8]. While next-generation control technologies are available, (particularly for point sources; [12,13]), attendant costs are significant, and a credible level of confidence in realized outcomes is necessary. In this regard, uncertainty has been expressed regarding the efficacy of load management in reducing nuisance growth and in the system-wide consequences of implementing those reductions [11], e.g.,

- With respect to efficacy, will reduction in local source phosphorus loading lead to measurable improvement if offshore forcing through cross-margin transport of SRP (for direct uptake by Cladophora) and PP (for conversion to SRP in the nearshore by dreissenids) have the capacity to sustain nuisance conditions of algal growth [11,14-16]?

- With respect to consequences, will reductions in phosphorus loading seeking mitigation of nuisance conditions in the nearshore promote oligotrophication and exacerbate the reductions in lake-wide ecosystem productivity presently observed to impact commercial, recreational, and native fish populations in the offshore? ([17]; see also [18], with respect to the Dual Challenge).

Three studies performed on Lake Ontario demonstrate the uncertainty related to offshore forcing. Higgins et al. [7] (p. 116), conducted a seven-site lake wide survey of peak Cladophora biomass and nutrient status (stored P content) and concluded that "there was little evidence that $\mathrm{P}$ from metabolic waste products of dreissenid mussels was sufficient to produce severe blooms [of Cladophora] in the absence of localized P enrichment." Simulations performed by Auer et al. [12] predicted a successful remediation of locally forced nuisance growth through implementation of advanced technology for P removal. 
Those simulations included offshore ambient SRP but not offshore PP forcing. Contrasting findings have been reported for Lake Ontario as well. For example, Howell [16] (p. 103) reported nuisance levels of Cladophora at a site on Lake Ontario seemingly away from sources of local P enrichment.

Similar contrasts have been reported for Lake Michigan. Bravo et al. [19] combined field monitoring and mathematical modeling of the phosphorus-Cladophora dynamic at sites influenced by the discharge from the South Shore Wastewater Treatment Plant (Milwaukee, WI). The results of biophysical modeling exercises indicated that phosphorus and Cladophora biomass associated with the discharge extended for tens of kilometers in the longshore and $\sim 2 \mathrm{~km}$ in the offshore directions, a clear case of local forcing. Simulation results further demonstrated that the system was responsive to reduction of $P$ discharges from that point source. However, high densities of Cladophora biomass have also been documented in northern Lake Michigan (e.g., North and South Manitou Islands and nearshore waters at Sleeping Bear National Lakeshore; Bootsma, unpublished; [11]). These sites are remote from any local $\mathrm{P}$ source, indicating that Cladophora growth must rely on supplies from open lake waters [11].

The contrasting findings observed for both Lake Ontario and Lake Michigan have resulted in a level of uncertainty that constitutes an existential barrier to the development of policies and regulations providing relief from the impacts of nuisance Cladophora growth. The Great Lakes Water Quality Agreement has adopted a precautionary approach in addressing serious threats (such as the long standing and extant Cladophora problem), stating that "lack of full scientific certainty shall not be used as a reason for postponing costeffective measures to prevent environmental degradation." Our work sought to contribute to the body of knowledge regarding both the efficacy and consequences concerns, helping to resolve the management gridlock hindering progress in managing the phosphorusCladophora dynamic.

\section{Objectives and Approach}

A key feature of the nearshore phosphorus shunt hypothesis of Hecky et al. [8], that dreissenid recycling of particulate matter can yield ecologically meaningful levels of SRP, has been well validated through field measurements $[20,21]$. It has been further demonstrated that the rate of SRP excretion by mussels increases with increasing ambient PP concentration [22]. Our objective, stated as a guiding question, is thus:

- Would ambient nearshore SRP concentrations, determined solely by cross-margin transport of offshore SRP and PP (the latter subsequently mineralized to SRP in the nearshore by mussels), be sufficient to support nuisance growth of Cladophora?

Beyond addressing the efficacy concern, attainment of this objective would provide an upper bound for SRP and PP concentrations in the offshore necessary to protect nearshore waters from Cladophora proliferation. That upper bound would offer guidance for future work seeking to balance eutrophication potential in the nearshore and oligotrophication in the offshore, the consequences the concern of the Dual Challenge. We sought to achieve our objectives by linking a hydrodynamic model simulating cross-margin transport and a biokinetic model simulating the ecophysiology of dreissenid P recycling.

\section{Methods}

\subsection{Study Site}

The study site for this research was Good Harbor Bay (Lake Michigan), part of the Sleeping Bear Dunes National Lakeshore (Figure 1a). The site is particularly appropriate for our study, as it was the location for research on mussels and bottom boundary layer phosphorus [21], has been reported to host high densities of Cladophora biomass [11] and is a component of the USGS Great Lakes Cladophora survey [23]. Additionally, the National Lakeshore has received considerable public attention with respect to beach deposition of algal debris. 


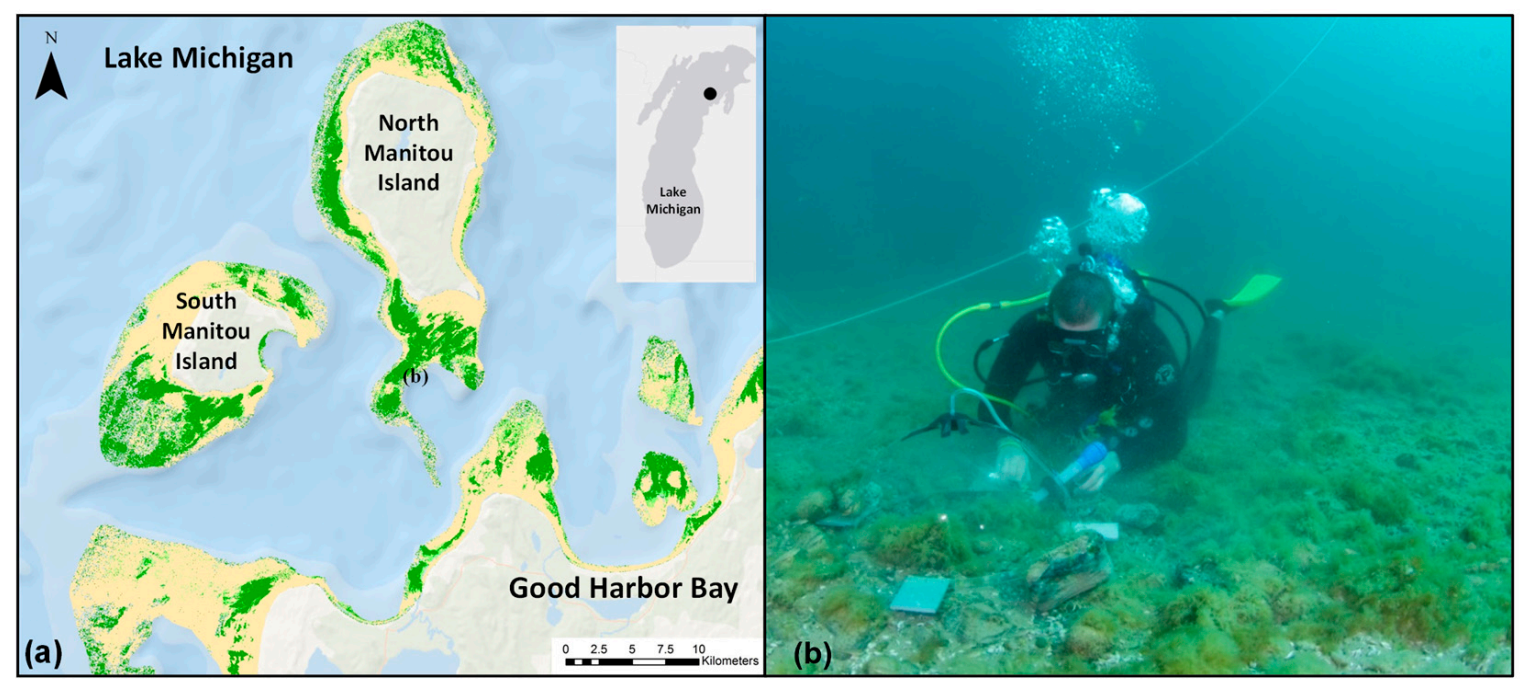

Figure 1. Good Harbor Bay study site: (a) geography and distribution of colonized (Cladophora; green) and uncolonized (sand; tan) substrate (courtesy of Michigan Tech Research Institute); (b) bottom substrate colonization by Cladophora and mussels (2011, 8-m depth; with permission of Aaron I. Dayton).

No significant local sources of phosphorus have been identified at Good Harbor Bay, and thus, it may be assumed that Cladophora growth there is supported by SRP and mussel recycling of particulate phosphorus delivered from offshore waters. The location is influenced by a broad range of mass transport conditions, including direct exposure to the open lake, and shielding by islands (Figure 1a). Good Harbor Bay has a maximum depth of $45 \mathrm{~m}$, with a system-wide average depth of $21 \mathrm{~m}$. Bottom types include sand and cobbles, the latter colonized by Cladophora and quagga mussels (Figure 1b; [21]). Triplicate measurements of Cladophora biomass were made at 3, 6, 10, and $18 \mathrm{~m}$ in 2019 [23]. The season average (Jun.-Aug.) biomass density was $47 \pm 28 \mathrm{gDW} \cdot \mathrm{m}^{-2}$ over depths of $3-6 \mathrm{~m}$, with maxima of 103 and $110 \mathrm{gDW} \cdot \mathrm{m}^{-2}$ reported for two replicates at the 3-m depth in June and $103 \mathrm{gDW} \cdot \mathrm{m}^{-2}$ for a single collection in July. Cladophora density declined markedly at 18 $\mathrm{m}$ (light limitation; [3]) averaging $17 \pm 16 \mathrm{gDW} \cdot \mathrm{m}^{-2}$, with a maximum of $47 \mathrm{gDW} \cdot \mathrm{m}^{-2}$ in July. These average biomass densities are well below those characteristic of nuisance conditions.

Dreissenids in Lake Michigan are now dominated by the quagga mussel, Dreissena rostriformis bugensis [24]. There are three records of sampling in Good Harbor Bay. In 2011, Dayton et al. [21] reported densities of 500 individuals $\cdot \mathrm{m}^{-2}$ (on a mix of sand and rocky substrate) and 3500 individuals $\cdot \mathrm{m}^{-2}$ (on a continuous bed of rocky substrate), both at 8-m depth. Sampling in 2019, LimnoTech [25] reported average mussel densities of $4400 \pm 1275$ individuals $\cdot \mathrm{m}^{-2}$ at an 8-10 $\mathrm{m}$ deep site. Przybyla-Kelly et al. [23] sampled depths of 3, 6, 10, and $18 \mathrm{~m}$ in 2018 and 2019. Mussel density was low at the 3-m site, with a median of 27 individuals $\cdot \mathrm{m}^{-2}$ and a maximum of 267 individuals $\cdot \mathrm{m}^{-2}$. At depths of $6-18 \mathrm{~m}$, the median density was reported to be 2080 individuals $\cdot \mathrm{m}^{-2}$. We carried forward a mussel density of 1796 individuals $\cdot \mathrm{m}^{-2}$ calculated as the simple average of the measurements listed above for depths ranging from 3-18 $\mathrm{m}([21,23,25])$. In biokinetic applications, this representative value may be expressed as a mussel biomass density of $15,266 \mathrm{mgAFDW} \cdot \mathrm{m}^{-2}$ (ash-free dry weight). The conversion was performed based on the representative mussel density and length-weight metrics developed specifically for Good Harbor Bay by LimnoTech [25]: a mean shell length of $15 \mathrm{~mm}$, a ratio of shell-free dry weight to shell length of 0.67 , and a ratio of ash-free dry weight to shell free dry weight of $0.85[26,27]$. The range of mussel biomass densities used in performing sensitivity analyses was $0-50,000 \mathrm{mgAFDW} \cdot \mathrm{m}^{-2}$, based on a lake-wide benthic survey of Lake Michigan performed in 2010 by Nalepa et al. [24]. 


\subsection{Framework for Modeling the Mussel-Phosphorus Dynamic}

Our biophysical modeling approach draws upon the capabilities of linked hydrodynamic and biokinetic models, with the former simulating cross-margin mass transport of water and P components (PP and SRP) across the nearshore-offshore boundary (margin) and the latter simulating mussel filtration of $\mathrm{PP}$ and attendant $\mathrm{P}$ recycling (Figure 2). In this process-oriented study, the biokinetic model was applied to a completely mixed nearshore control volume, assuming horizontal and vertical homogeneity in PP and SRP and in mussel distribution and density. This approach is appropriate for our objective to explore mussel mediation of nearshore ambient SRP levels supported only by offshore SRP and PP reserves and eases the computational burden so that we may focus on process-based (biokinetic) features and more rigorously characterize model sensitivity and uncertainty. We note that concentrations of $\mathrm{SRP}_{\text {nearshore }}$ predicted for low concentrations of $\mathrm{PP}_{\text {offshore }}\left(<0.5 \mathrm{mgP} \cdot \mathrm{m}^{-3} \cdot \mathrm{d}^{-1}\right)$ in combination with low rates of cross-margin transport $\left(<2 \times 10^{8} \mathrm{~m}^{3} \cdot \mathrm{d}^{-1}\right)$ and / or high biomass densities (most commonly $\left.>45,000 \mathrm{mgAFDW}{ }^{-1} \cdot \mathrm{m}^{-2}\right)$ represent non-equilibrium (starvation) conditions. While calculated rates are applicable in the time frame of our simulation, the occurrence of starvation conditions would lead to mussel mortality and establishment of a new equilibrium condition over a longer time frame (see [28]).

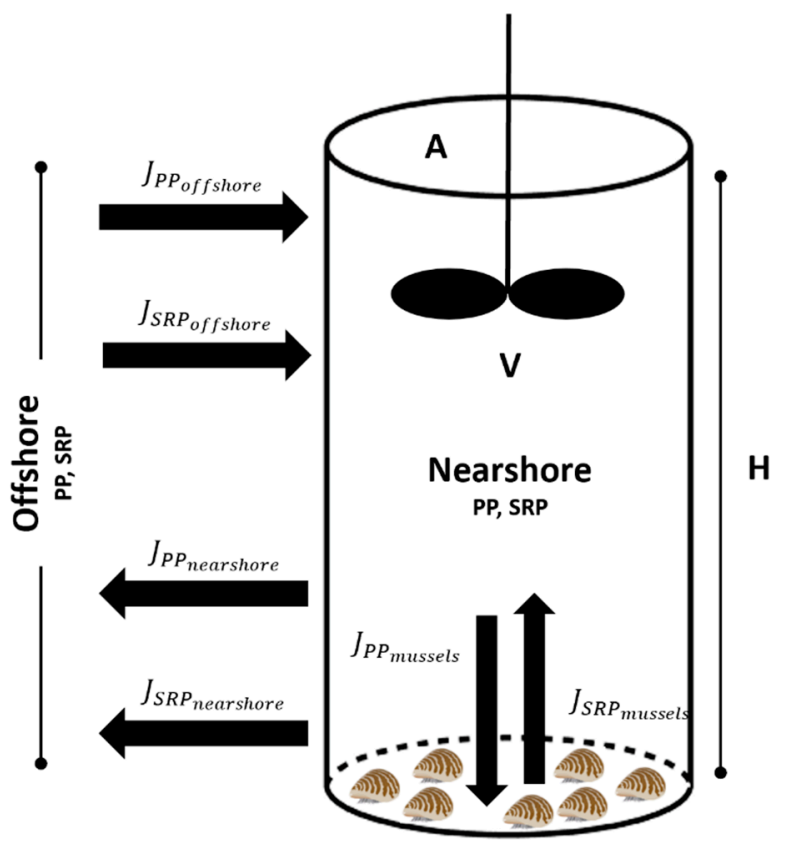

Figure 2. Conceptual diagram of the model framework used to simulate the mussel-phosphorus dynamic. Arrows represent the mass flux of PP and SRP $\left(\mathrm{mgP} \cdot \mathrm{d}^{-1}\right)$ across the nearshore-offshore and sediment-water boundaries. Implicit here are the roles of the two models: one, hydrodynamic in nature, simulating cross-margin transport and the other, biokinetic, simulating mussel PP entrainment and SRP excretion.

Models of mussel biokinetics typically take the form of a mass balance on one of three state variables: phosphorus [21,28], carbon [17,29], or mussel biomass [30], with differences dependent upon research goals and the larger model framework in which they are imbedded (e.g., NPZDM). The mass balance used here (Figure 2) is phosphorus-based and includes a source term (filtration, PP) and three sink terms (egestion of pseudo-feces, PP; excretion of feces, PP; and excretion in the soluble phase, SRP). Phosphorus excreted in the soluble form is primarily SRP [31,32]. Mosely and Bootsma [33] measured dissolved organic phosphorus excretion (DOP, $\mathrm{mgP} \cdot \mathrm{m}^{-3}$ ) as well, but negligible amounts of organic $\mathrm{P}$ were generated by mussels greater than $\sim 5 \mathrm{mgDW} \cdot$ individual $^{-1}$. 
The mass balance is performed on PP and SRP in the nearshore, the former being the fuel for recycling and the latter the product of the process:

$$
\begin{gathered}
\mathrm{V} \cdot \frac{\mathrm{dPP} \text { nearshore }_{\mathrm{d}}}{\mathrm{dt}}=\mathrm{J}_{\mathrm{PP} \text {,offshore }}-\mathrm{J}_{\mathrm{PP} \text {, nearshore }}-\mathrm{J}_{\mathrm{PP} \text {, mussels }} \\
\mathrm{V} \cdot \frac{\mathrm{dSRP} \mathrm{nearshore}_{\text {e }}}{\mathrm{dt}}=\mathrm{J}_{\mathrm{SRP} \text {,offshore }}-\mathrm{J}_{\mathrm{SRP} \text {, nearshore }}+\mathrm{J}_{\mathrm{SRP} \text {,mussels }}
\end{gathered}
$$

where $\mathrm{V}$ is the control volume $\left(\mathrm{m}^{3}\right), \mathrm{PP}_{\text {nearshore }}$ and $\mathrm{SRP}_{\text {nearshore }}$ are the $\mathrm{P}$ component concentrations in the nearshore $\left(\mathrm{mgP} \cdot \mathrm{m}^{-3}\right), \mathrm{J}_{\mathrm{PP}, \text { offshore }}$ and $\mathrm{J}_{\mathrm{PP}, \text { nearshore }}$ and $\mathrm{J}_{\mathrm{SRP} \text {,offshore }}$ and $\mathrm{J}_{\mathrm{SRP} \text {,nearshore }}$ are the cross-margin fluxes for PP and SRP $\left(\mathrm{mgP} \cdot \mathrm{d}^{-1}\right)$, and $\mathrm{JPP}_{\mathrm{PP} \text {,mssels }}$ and JSRP,mussels are, respectively, the mussel filtration and excretion fluxes $\left(\mathrm{mgP}^{-\mathrm{d}^{-1}}\right)$.

Inspection of Figure 2 and Equations (1a) and (1b) reveals that levels of SRP in the nearshore are mediated by the interplay of mass fluxes at the nearshore-offshore and sediment-water boundaries. Replacing the mass fluxes in Equations (1a) and (1b) by their defining component terms yields

$$
\begin{aligned}
& \mathrm{V} \cdot \frac{\mathrm{dPP} P_{\text {nearshore }}}{\mathrm{dt}}=-\mathrm{J}_{\mathrm{PP} \text {, mussels }} \cdot \mathrm{A}+\mathrm{Q} \cdot \mathrm{PP}_{\text {offshore }}-\mathrm{Q} \cdot \mathrm{PP}_{\text {nearshore }} \\
& \mathrm{V} \cdot \frac{\mathrm{dSRP}_{\text {nearshore }}}{\mathrm{dt}}=\mathrm{J}_{\text {SRP, mussels }} \cdot \mathrm{A}+\mathrm{Q} \cdot \mathrm{SRP}_{\text {offshore }}-\mathrm{Q} \cdot \mathrm{SRP}_{\text {nearshore }}
\end{aligned}
$$

where $\mathrm{J}_{\mathrm{PP} \text {,mussels }}^{\prime}$ is the PP flux density resulting from mussel filtration $\left(\mathrm{mgP} \cdot \mathrm{m}^{-2} \cdot \mathrm{d}^{-1}\right)$, $\mathrm{J}_{\text {SRP, mussels }}^{\prime}$ is the SRP flux density for mussel excretion $\left(\mathrm{mgP} \cdot \mathrm{m}^{-2} \cdot \mathrm{d}^{-1}\right)$, A is the bottom area of the control volume $\left(\mathrm{m}^{2}\right), \mathrm{Q}$ is the cross-margin flow $\left(\mathrm{m}^{3} \cdot \mathrm{d}^{-1}\right)$, and $\mathrm{PP}_{\text {offshore }}$ and $\mathrm{SRP}_{\text {offshore }}$ are the $\mathrm{P}$ component concentrations in the offshore $\left(\mathrm{mgP} \cdot \mathrm{m}^{-3}\right)$. Dividing both sides of Equations (2a) and ( $2 \mathrm{~b}$ ) by the control volume $(\mathrm{V})$ yields

$$
\begin{gathered}
\frac{\mathrm{dPP}_{\text {nearshore }}}{\mathrm{dt}}=-\frac{\mathrm{J}_{\mathrm{PP} \text {,mussels }}}{\mathrm{H}}+\frac{\mathrm{Q} \cdot \mathrm{PP}_{\text {offshore }}-\mathrm{Q} \cdot \mathrm{PP}_{\text {nearshore }}}{\mathrm{V}} \\
\frac{\mathrm{dSRP}_{\text {nearshore }}}{\mathrm{dt}}=\frac{\mathrm{J}_{\mathrm{SRP} \text {,mussels }}^{\prime}}{\mathrm{H}}+\frac{\mathrm{Q} \cdot \mathrm{SRP}_{\text {offshore }}-\mathrm{Q} \cdot \mathrm{SRP}_{\text {nearshore }}}{\mathrm{V}}
\end{gathered}
$$

where $\mathrm{H}$ is the control volume depth $(\mathrm{m})$.

Calculation of the PP flux density for filtration $\left(\mathrm{J}_{\mathrm{PP} \text {,mussels }}^{\prime}, \mathrm{mgP} \cdot \mathrm{m}^{-2} \cdot \mathrm{d}^{-1}\right)$ involves two steps. First, the mussel-specific rate of PP filtration $\left(\mathrm{F}_{\mathrm{PP}} \mathrm{mgP} \cdot \mathrm{mgAFDW}^{-1} \cdot \mathrm{d}^{-1}\right)$ is determined as the product of the mussel-specific volumetric filtration rate $\left(\mathrm{F}_{\mathrm{vol}}, \mathrm{m}^{3} \cdot \mathrm{mgAFDW} \cdot \mathrm{d}^{-1}\right)$ and $\mathrm{PP}_{\text {nearshore }}\left(\mathrm{mgP} \cdot \mathrm{m}^{-3}\right)$,

$$
\mathrm{F}_{\mathrm{PP}}=\mathrm{F}_{\mathrm{vol}} \cdot \mathrm{PP}_{\text {nearshore }}
$$

and recognizing that the mussel-specific SRP excretion rate $\left(E_{S R P}, \mathrm{mgP} \cdot \mathrm{mgAFDW}^{-1} \cdot \mathrm{d}^{-1}\right)$ will be a fraction ( $f$, dimensionless) of the PP captured by filtration $\left(\mathrm{F}_{\mathrm{PP}}\right)$,

$$
\mathrm{E}_{\mathrm{SRP}}=f \cdot \mathrm{F}_{\mathrm{vol}} \cdot \mathrm{PP}_{\text {nearshore }}
$$

Substituting from Equations (4a) and (4b) and multiplying by the mussel biomass density $\left(\mathrm{B}, \mathrm{mgAFDW} \cdot \mathrm{m}^{-2}\right)$ yields the flux densities for PP filtration $\left(\mathrm{J}_{\mathrm{PP}, \text { mussels }}^{\prime}, \mathrm{mgP} \cdot \mathrm{m}^{-2} \cdot \mathrm{d}^{-1}\right)$ and SRP excretion $\left(\mathrm{J}_{\text {SRP, mussels }}^{\prime}, \mathrm{mgP} \cdot \mathrm{m}^{-2} \cdot \mathrm{d}^{-1}\right)$,

$$
\begin{gathered}
\mathrm{J}_{\mathrm{PP}, \text { mussels }}^{\prime}=\mathrm{F}_{\mathrm{vol}} \cdot \mathrm{PP}_{\text {nearshore }} \cdot \mathrm{B} \\
\mathrm{J}_{\text {SRP,mussels }}^{\prime}=f \cdot \mathrm{F}_{\mathrm{vol}} \cdot \mathrm{PP}_{\text {nearshore }} \cdot \mathrm{B}
\end{gathered}
$$

Finally, substituting Equations (5a) and (5b) to Equations ( $3 a$ ) and ( $3 b$ ) and re-arranging yields the governing equations for the nearshore P-mussel model: 


$$
\begin{gathered}
\frac{\mathrm{dPP}_{\text {nearshore }}}{\mathrm{dt}}=\frac{\mathrm{Q} \cdot\left(\mathrm{PP}_{\text {offshore }}-\mathrm{PP}_{\text {nearshore }}\right)}{\mathrm{V}}-\frac{F_{\text {vol }} \cdot \mathrm{B} \cdot \mathrm{PP}_{\text {nearshore }}}{\mathrm{H}} \\
\frac{\mathrm{dSRP}_{\text {nearshore }}}{\mathrm{dt}}=\frac{\mathrm{Q} \cdot\left(\mathrm{SRP}_{\text {offshore }}-\mathrm{SRP}_{\text {nearshore }}\right)}{\mathrm{V}}+f \cdot \frac{F_{\text {vol }} \cdot \mathrm{B} \cdot \mathrm{PP} \mathrm{P}_{\text {nearshore }}}{\mathrm{H}}
\end{gathered}
$$

In this form, solution of the PP and SRP mass balances requires:

- $\quad$ parameterization of the biokinetic coefficients $\mathrm{F}_{\mathrm{vol}}$ and $f$ (Section 3.2.1);

- $\quad$ specification of mussel biomass density (Section 3.1);

- $\quad$ specification of offshore PP and SRP concentrations (Section 3.2.2);

- $\quad$ specification of control volume physical characteristics (H and V; (Section 3.2.3)); and

- determination of the rate of cross margin flow (Q; Section 3.2.3).

\subsubsection{Parameterization of the Biokinetic Coefficients $\mathrm{F}_{\mathrm{vol}}$ and $f$}

Implementation of the biokinetic model requires specification of two coefficients, the mussel-specific filtration rate $\left(\mathrm{F}_{\mathrm{vol}}\right)$ and the PP to SRP conversion efficiency $(f)$. Filtration, the means by which mussels acquire particulate matter, is known to be influenced by water temperature $[34,35]$ and by food quality and quantity $[35,36]$. We did not treat temperature and food-quality mediation here, as these are seasonal and nutritional conditions beyond the resolution of our steady-state analysis. Instead, we focused on filtration-rate mediation by mussel body size at the mussel-specific scale and mussel density at the population scale [37]. Literature derived estimates of $\mathrm{F}_{\mathrm{vol}}$ range from $10^{-4}$ to $10^{-3} \mathrm{~m}^{3} \cdot \mathrm{mgAFDW}^{-1} \mathrm{~d}^{-1}$ (Figure 3). We ascribe this order of magnitude variation to cross-study non-normalization for temperature and food quality and quantity as well as techniques for mussel harvest, maintenance and manipulation, and experimental design [38]. Here, we adopted a value for $\mathrm{F}_{\mathrm{vol}}=4.75 \times 10^{-4} \mathrm{~m}^{3} \cdot \mathrm{mgAFDW}^{-1} \cdot \mathrm{d}^{-1}$ as a representative rate for use in the biokinetic model. This rate is the median value for ranges of $\mathrm{F}_{\mathrm{vol}}$ reported by Diggins et al. [39]; Vanderploeg et al. [34]; and Xia et al. [40] (Figure 3). The upper $\left(6.46 \times 10^{-4} \mathrm{~m}^{3} \cdot \mathrm{mgAFDW}^{-1} \cdot \mathrm{d}^{-1}\right)$ and lower $\left(3.04 \times 10^{-4} \mathrm{~m}^{3} \cdot \mathrm{mgAFDW}^{-1} \cdot \mathrm{d}^{-1}\right)$ quartiles of these ranges were utilized in sensitivity analysis.

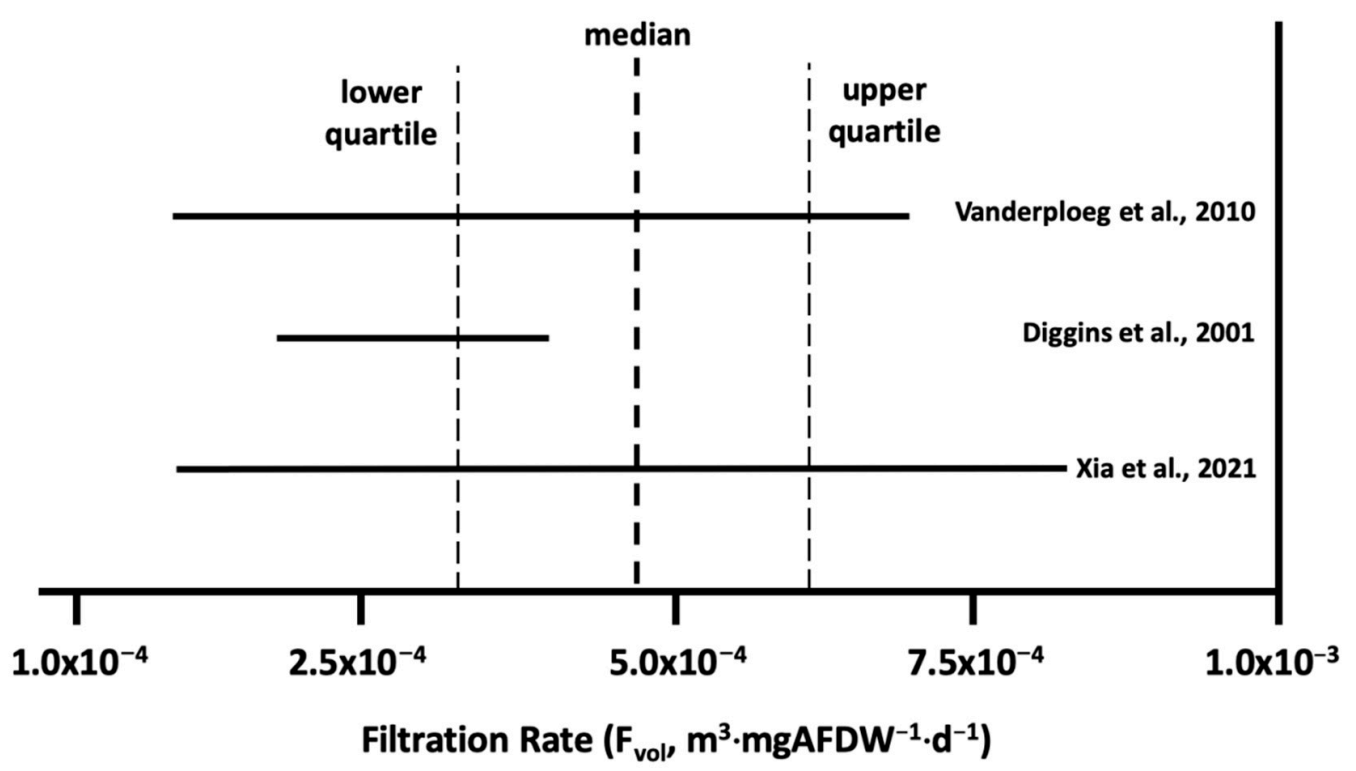

Figure 3. Ranges in quagga mussel filtration rates $\left(\mathrm{F}_{\mathrm{vol}}, \mathrm{m}^{3} \cdot \mathrm{mgAFDW} \mathrm{W}^{-1} \cdot \mathrm{d}^{-1}\right.$; horizontal lines $)$ reported in three studies were used to compute the median rate for data pooled from those studies $\left(\mathrm{F}_{\mathrm{vol}}=4.75 \times 10^{-4} \mathrm{~m}^{3} \cdot \mathrm{mgAFDW}^{-1} \cdot \mathrm{d}^{-1}\right.$ (vertical bold dashed line) and taken as the representative value for this research. The vertical dashed lines represent the lower and upper quartiles for those data used in sensitivity analysis. 
Proceeding from the work of Bootsma [22] and Mosely and Bootsma [33], one may determine the PP to SRP mussel conversion efficiency $(f)$ as the ratio of the mussel-specific rate of SRP excretion $\left(\mathrm{E}_{\mathrm{SRP}}, \mathrm{mgP} \cdot \mathrm{mgDW}^{-1} \cdot \mathrm{d}^{-1}\right)$ to the mussel-specific rate of PP filtration $\left(\mathrm{F}_{\mathrm{PP}}, \mathrm{mgP} \cdot \mathrm{mgDW}^{-1} \cdot \mathrm{d}^{-1}\right)$,

$$
f=\frac{\mathrm{E}_{\mathrm{SRP}}}{\mathrm{F}_{\mathrm{PP}}}
$$

Excluding the small quantities of P retained in mussel biomass [41], $\mathrm{F}_{\mathrm{PP}}$ may be seen to equal the sum of the mussel-specific rates of SRP excretion $\left(\mathrm{mgP} \cdot \mathrm{mgDW}^{-1} \cdot \mathrm{d}^{-1}\right)$ and PP pseudo-feces egestion and feces excretion $\left(E_{P P}, \mathrm{mgP} \cdot \mathrm{mgDW}^{-1} \cdot \mathrm{d}^{-1}\right)$,

$$
f=\frac{\mathrm{E}_{\mathrm{SRP}}}{\mathrm{E}_{\mathrm{SRP}}+\mathrm{E}_{\mathrm{PP}}}
$$

Again, ignoring $\mathrm{P}$ retained as biomass and substituting from Equation (4a) to Equation (7) yields

$$
f=\frac{\mathrm{E}_{\mathrm{SRP}}}{\mathrm{F}_{\mathrm{vol}} \cdot \mathrm{PP}}
$$

Thus, the approaches presented as Equations (8) and (9), similar in nature but drawing on different aspects of experimental measurement, are available for estimating values of $f$.

Mosley and Bootsma [33] measured rates of egestion and excretion for profunda morph quagga mussels in Lake Michigan and developed functions relating those rates to mussel biomass (dry weight, DW):

$$
\begin{aligned}
& E_{\mathrm{SRP}}=0.01 \cdot \mathrm{DW}^{-0.343} \\
& \mathrm{E}_{\mathrm{PP}}=0.0686 \cdot \mathrm{DW}^{-0.791}
\end{aligned}
$$

We calculated conversion efficiency by applying Equations (10) and (11) to Equation (8) for mussel biomass ranging from $0.08 \mathrm{mgDW}$ (2-mm shell length) to $40 \mathrm{mgDW}$ (30-mm shell length). This yields values of $f$ ranging from $0.05-0.43$ with a value of $f=0.29$ for a shell length of $15 \mathrm{~mm}$, the average length for Good Harbor Bay [25].

In a previous study focusing on the shallow morph quagga mussel in Lake Michigan, Bootsma [22] developed a relationship for calculating SRP excretion as a function of mussel biomass:

$$
\mathrm{E}_{\mathrm{SRP}}=0.1525 \cdot \mathrm{DW}^{-0.7617}
$$

However, no relationship was provided between shallow morph $\mathrm{E}_{\mathrm{PP}}$ and DW (as was done for the profunda morph, Equation (11)). Therefore, Equation (9) was utilized, applying an $\mathrm{F}_{\mathrm{vol}}$ value of $4.18 \times 10^{-4} \mathrm{~m}^{3} \cdot \mathrm{mgDW}^{-1} \cdot \mathrm{d}^{-1}$, converted from the representative value $\left(\mathrm{F}_{\mathrm{vol}}=4.75 \times 10^{-4} \mathrm{~m}^{3} \cdot \mathrm{mgAFDW}{ }^{-1} \cdot \mathrm{d}^{-1}\right)$ using an AFDW:DW ratio of 0.88 [26]. In making the calculation, we used a PP value of $6.8 \mathrm{mgP} \cdot \mathrm{m}^{-3}$, the concentration reported by Bootsma [22] for shallow morph site measurements. The resulting values of $f$ ranged from $0.21-0.49$ for a mussel biomass of $5-15 \mathrm{mgDW}$, a range corresponding to shell lengths of 14-25 mm, mid-range for shallow morph populations (Figures 3 and 4 of Mosley and Bootsma [33]). For a 15-mm quagga mussel (the average mussel length in Good Harbor Bay), the value of $f$ is 0.29 . 


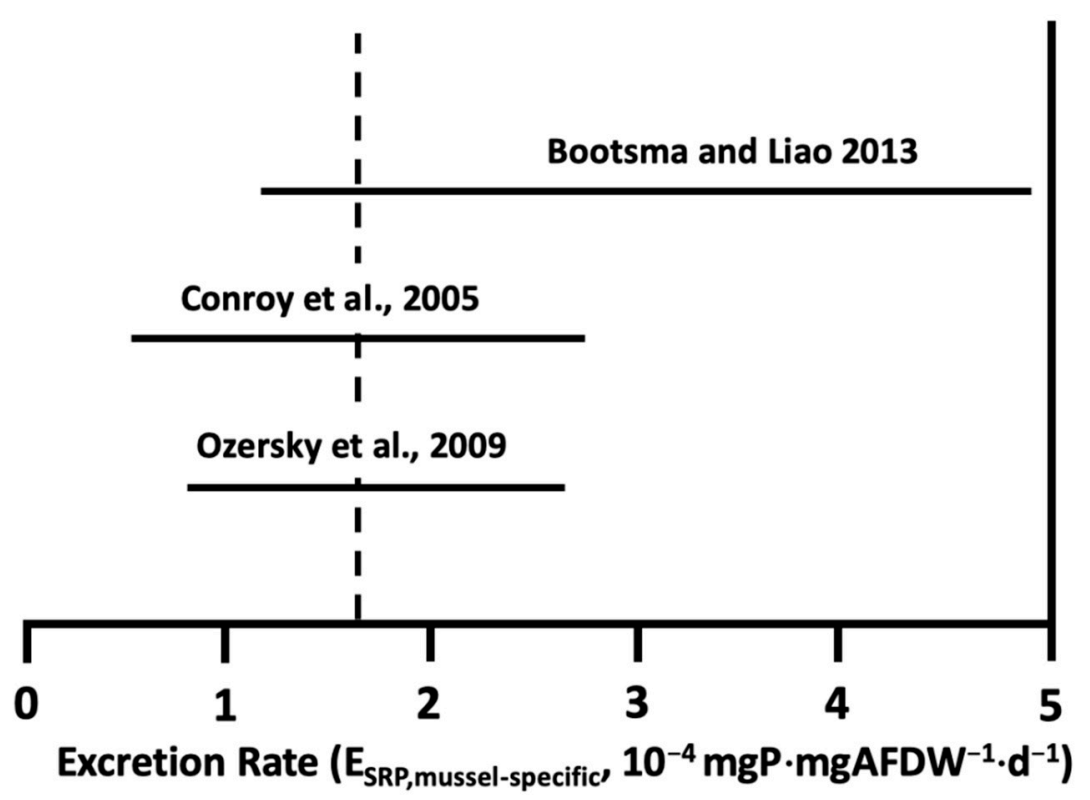

Figure 4. Comparison of measured quagga mussel SRP excretion rates ( $E_{S R P}$; horizontal lines) with the rate calculated according to Equation (10) (dashed line) for the representative value of $\mathrm{F}_{\mathrm{vol}}$ $\left(4.75 \times 10^{-4} \mathrm{~m}^{3} \cdot \mathrm{mgAFDW}{ }^{-1} \cdot \mathrm{d}^{-1}\right), \mathrm{PP}$ at Good Harbor Bay $\left(1.2 \mathrm{mgP} \cdot \mathrm{m}^{-3}\right)$, and the representative value of $f(0.29)$.

Based on calculations made using results from Bootsma [22] and Mosely and Bootsma [33], we carried forward $f=0.29$ as the representative conversion efficiency for application to shallow-water habitats co-inhabited by mussels and Cladophora. This representative value is comparable to estimates of $f$ applied in other modeling studies focusing on the quagga mussel in Lake Michigan ([17], $f=0.35$ and [29], $f=0.30$ ). We further examined selection of the coefficient by calculating ESRP using Equation (4b) with $f=0.29$, $\mathrm{F}_{\mathrm{vol}}=4.75 \times 10^{-4} \mathrm{~m}^{3} \cdot \mathrm{mgAFDW}^{-1} \cdot \mathrm{d}^{-1}($ Table 1$)$, and $\mathrm{PP}_{\text {nearshore }}=1.21 \mathrm{mgP} \cdot \mathrm{m}^{-3}(\mathrm{Good}$ Harbor Bay, [21]). The resulting rate, $1.65 \times 10^{-4} \mathrm{mgSRP} \cdot \mathrm{mgDW}^{-1} \cdot \mathrm{d}^{-1}$, is consistent with those reported from the literature (Figure 4). We applied conversion efficiencies of $f=0.2$, $0.3,0.4$, and 0.5 in performing sensitivity analyses.

\subsubsection{The Phosphorus Environment}

Application of the linked hydrodynamic-biokinetic model requires specification of offshore concentrations of SRP and PP. It is critical that the phosphorus environment be carefully and reliably described because the phosphorus-Cladophora dynamic is played out across a narrow range of SRP concentrations $\left(0-2 \mathrm{mgP} \cdot \mathrm{m}^{-3}\right)$ approaching the limit of detection (typically $0.5 \mathrm{mgP} \cdot \mathrm{m}^{-3}$ ). Here, we refer to monitoring performed by the U.S. EPA Great Lakes Water Quality Survey available through the GLENDA database. These surveys were performed in spring (late March to early May) and summer (late July to mid-September) from 1983-2018 (excepting 1994). We selected 11 stations on Lake Michigan having a maximum depth of $\geq 90 \mathrm{~m}$ and a monitoring record of 30 or more years (Appendix A, Figure A1). The database reports concentrations of total phosphorus (TP), total dissolved phosphorus (TDP), and SRP, from which PP and dissolved organic phosphorus (DOP) may be determined. 
Table 1. Coefficients and model inputs used in simulations: (a) median concentrations and ranges for soluble reactive and particulate phosphorus in the offshore waters of Lake Michigan as applied in sensitivity analyses and management simulations for the post-dreissenid period, (b) model inputs and coefficients representative of conditions in Good Harbor Bay for the post-dreissenid period, (c) median concentrations for soluble reactive and particulate phosphorus in the offshore waters of Lake Michigan for the pre-dreissenid period, and (d) median concentrations for soluble reactive and particulate phosphorus in the east side and west side nearshore waters of Lake Michigan for the post-dreissenid period.

\begin{tabular}{|c|c|c|}
\hline Model Input or Coefficient & Value & Range \\
\hline \multicolumn{3}{|c|}{ (a). Model inputs and coefficients for Good Harbor Bay, post-dreissenid period } \\
\hline Mussel biomass density $\left(\mathrm{B}, \mathrm{mgAFDW} \cdot \mathrm{m}^{-2}\right)$ & 15,266 & $0-50,000$ \\
\hline Mussel filtration rate $\left(\mathrm{F}_{\mathrm{vol}}, \times 10^{-4} \mathrm{~m}^{3} \cdot \mathrm{mgAFDW}^{-1} \cdot \mathrm{d}^{-1}\right)$ & 4.75 & $3.04,4.75,6.46$ \\
\hline Mussel PP to SRP conversion efficiency ( $f$, d'less) & 0.29 & $0.2,0.3,0.4,0.5$ \\
\hline Rate of cross-margin flow $\left(\mathrm{Q}, \times 10^{8} \mathrm{~m}^{3} \cdot \mathrm{d}^{-1}\right)$ & 2.1 & $0.25,1.0,2.0,4.0,6.0$ \\
\hline \multicolumn{3}{|c|}{ (b). Phosphorus levels for the Lake Michigan offshore, post-dreissenid period } \\
\hline $\mathrm{SRP}$ in the offshore, $\mathrm{SRP}_{\text {offshore }}, \mathrm{mgP} \cdot \mathrm{m}^{-3}$ & 0.84 & $0.50,0.80,1.00,1.25,1.50$ \\
\hline $\mathrm{PP}$ in the offshore, $\mathrm{PP}_{\text {offshore }}, \mathrm{mgP} \cdot \mathrm{m}^{-3}$ & 1.05 & $0-7$ \\
\hline \multicolumn{3}{|c|}{ (c). Phosphorus levels for the Lake Michigan offshore, pre-dreissenid period } \\
\hline $\mathrm{SRP}$ in offshore waters $\left(\mathrm{SRP}_{\text {offshore }}, \mathrm{mgP} \cdot \mathrm{m}^{-3}\right)$ & 0.80 & \\
\hline $\mathrm{PP}$ in offshore waters, $\left(\mathrm{PP}_{\text {offshore }}, \mathrm{mgP} \cdot \mathrm{m}^{-3}\right)$ & 2.10 & \\
\hline \multicolumn{3}{|c|}{ (d). Phosphorus levels for the Lake Michigan nearshore, post-dreissenid period } \\
\hline $\mathrm{SRP}$ at nearshore east stations, $\mathrm{SRP}_{\text {nearshore }}, \mathrm{mgP} \cdot \mathrm{m}^{-3}$ & 1.45 & \\
\hline $\mathrm{SRP}$ at nearshore west stations, $\mathrm{SRP}_{\text {nearshore }}, \mathrm{mgP} \cdot \mathrm{m}^{-3}$ & 2.34 & \\
\hline $\mathrm{PP}$ at nearshore east stations, $\mathrm{PP}_{\text {nearshore }}, \mathrm{mgP} \cdot \mathrm{m}^{-3}$ & 5.70 & \\
\hline $\mathrm{PP}$ at nearshore west stations, $\mathrm{PP}_{\text {nearshore }} \mathrm{mgP} \cdot \mathrm{m}^{-3}$ & 6.12 & \\
\hline
\end{tabular}

We partitioned the full database into a $2 \times 2$ matrix (Spring, Summer, Surface, and Bottom) yielding four quadrants. Matrix pairs were examined for significant differences $(t$-test, $p \leq 0.05)$ in an effort to identify those that could be treated collectively as representative of offshore conditions. The Spring Surface vs. Spring Bottom pair exhibited the least significant difference. However, we limited further analysis to the Spring Surface quadrant (Appendix B, Table A2a), as that sampling aligns well temporally with the alga's growing season, capturing SRP levels during the period of active Cladophora growth and prior to SRP drawdown by phytoplankton. We examined the Spring Surface data set for significant differences among stations horizontally (north-south and east-west) and found none. Finally, differences in the Spring Surface subset were examined in a long-term context, i.e., for a period (1983-1992) in the pre-dreissenid period, prior to dreissenid invasion, and a period (2009-2018) in the post-dreissenid period, following colonization of Lake Michigan by dreissenid mussels (Appendix B, Table A2b). Striking changes in TP and several of its components were reported from the pre- to post-dreissenid periods (Figures 5 and 6). TP dropped $37 \%$ from 4.8 . to $3.0 \mathrm{mgP} \cdot \mathrm{m}^{-3}$, PP dropped $50 \%$ from 2.10 to $1.05 \mathrm{mgP} \cdot \mathrm{m}^{-3}$, and DOP dropped $38 \%$ from 1.60 to $1.00 \mathrm{mgP} \cdot \mathrm{m}^{-3}$; SRP levels modestly increased (5\%) from 0.80 to $0.84 \mathrm{mgP} \cdot \mathrm{m}^{-3}$. 


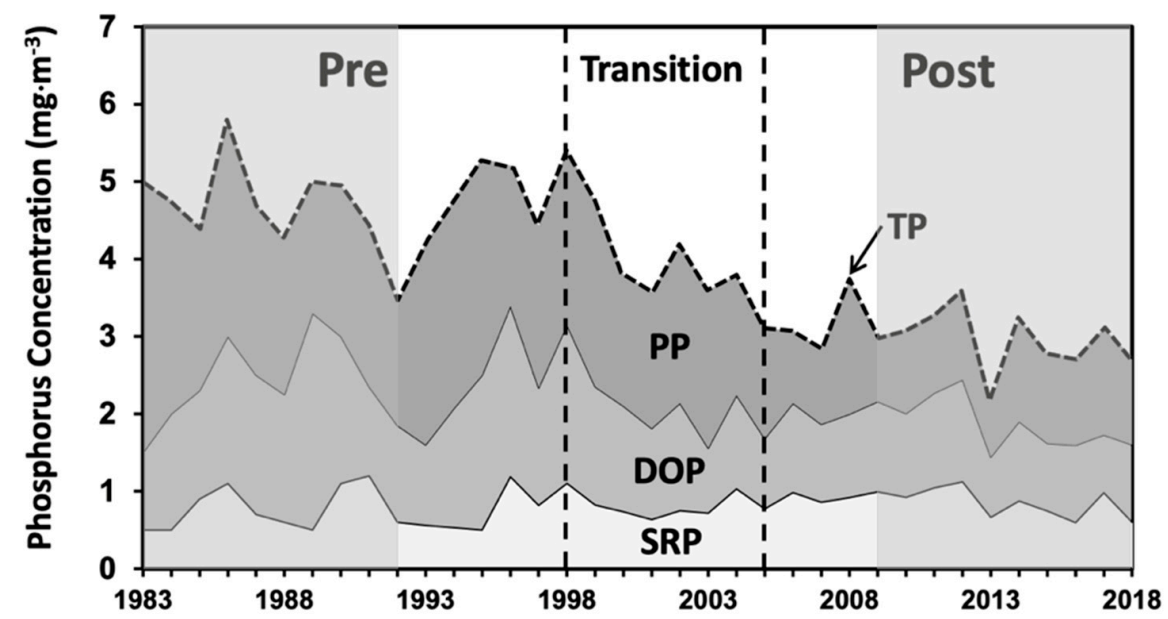

Figure 5. Total phosphorus (TP; bold dashed horizontal line) and contributions to TP from particulate (PP), dissolved organic (DOP), and soluble reactive (SRP) in the offshore waters of Lake Michigan over the pre-dreissenid (before 1998), transition (1998-2005), and post-dreissenid (after 2005) periods (delineated by bold vertical dashed lines). Data are those of U.S. EPA GLENDA, and period assignment follows that of Pothoven and Fahnenstiel [42]. Data analyzed in this research were drawn from 10-year periods within the pre- (1983-1992) and post- (2009-2018) dreissenid periods (shaded).

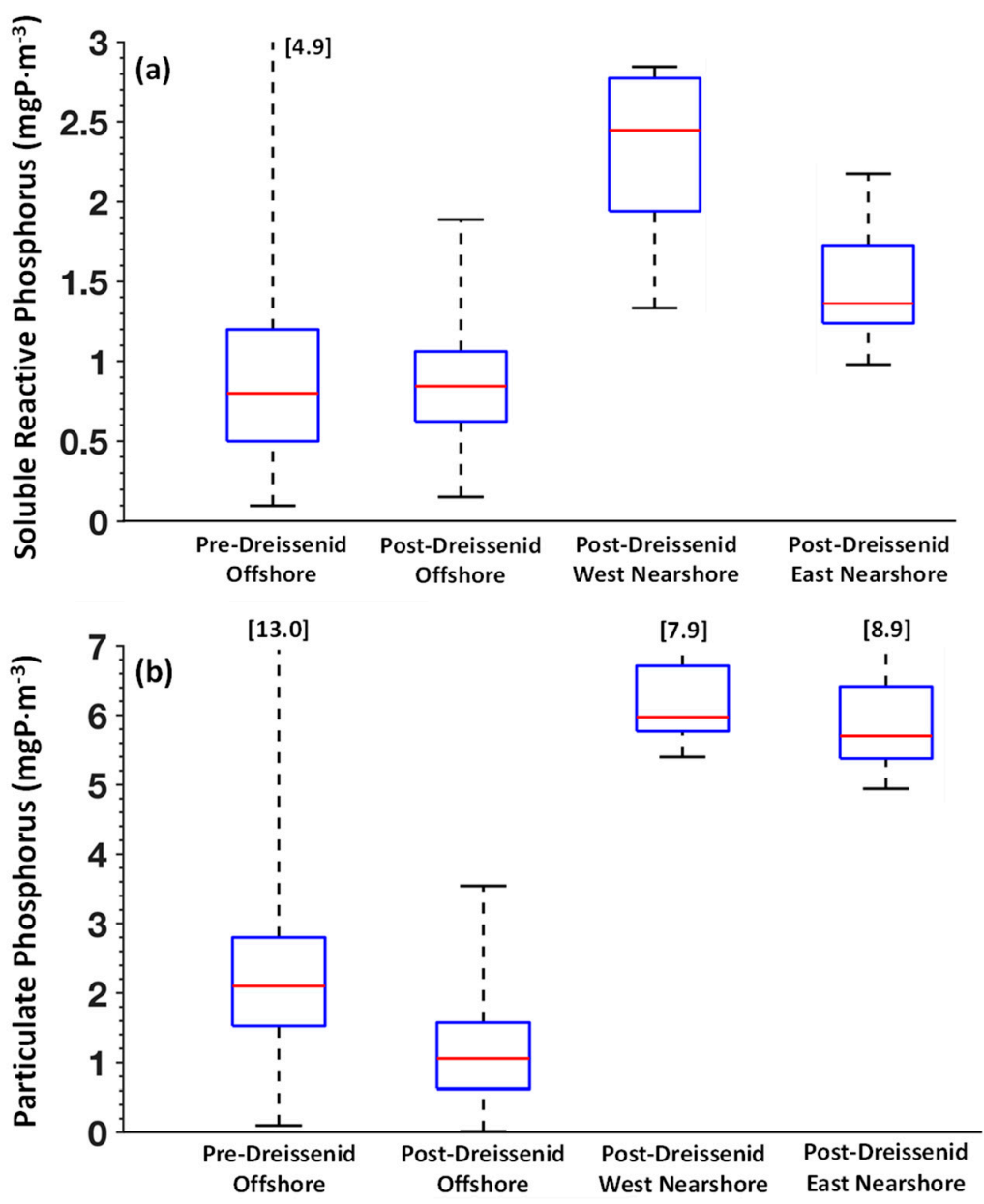

Figure 6. Box and whisker plots for: (a) soluble reactive phosphorus; (b) particulate phosphorus with the median (red line), lower quartile (blue box, bottom), upper quartile (blue box, top), maximum, and minimum for offshore waters in the pre-dreissenid and post-dreissenid periods (data of U.S. EPA GLENDA) and for nearshore waters in the post-dreissenid period (data of Yurista et al. [43]). 
As a basis for comparison to offshore conditions, we also examined monitoring results for TP, SRP, and PP obtained during a survey of the Lake Michigan nearshore performed by Yurista et al. [43] (Anne Cotter, U.S. EPA MED, personal communication) from 9-15 September 2010. Samples were collected at depths $<20 \mathrm{~m}$ at 15 stations along a $\sim 1000 \mathrm{~km}$ track encircling Lake Michigan (Appendix A, Figure A2). We separated the nearshore data set into east and west components, recognizing the potential impact of different levels of landscape activity. It is evident from this analysis that SRP concentrations (the source immediately available to Cladophora) were markedly higher in the nearshore than the offshore and higher along the west coast than the east (Figure 6; see also Appendix B, Table A2c).

\subsubsection{The 3-D Hydrodynamic Model: Simulating Cross-Margin Transport}

Flow patterns are complex at the nearshore-offshore boundary and within Good Harbor Bay, as strong coastal jets flow northeastward and southwestward along the boundary. As an example, monthly average flow for July 2018 was driven by a coastal jet moving northeastward along the boundary. Inflow was received at the northeast limit of the margin as a branch of the coastal jet and returned to join the coastal jet at the southwest limit of the margin. A bay-wide eddy was formed in the nearshore, reflecting the influence of variability in shoreline structure and bathymetry (Figure 7a).
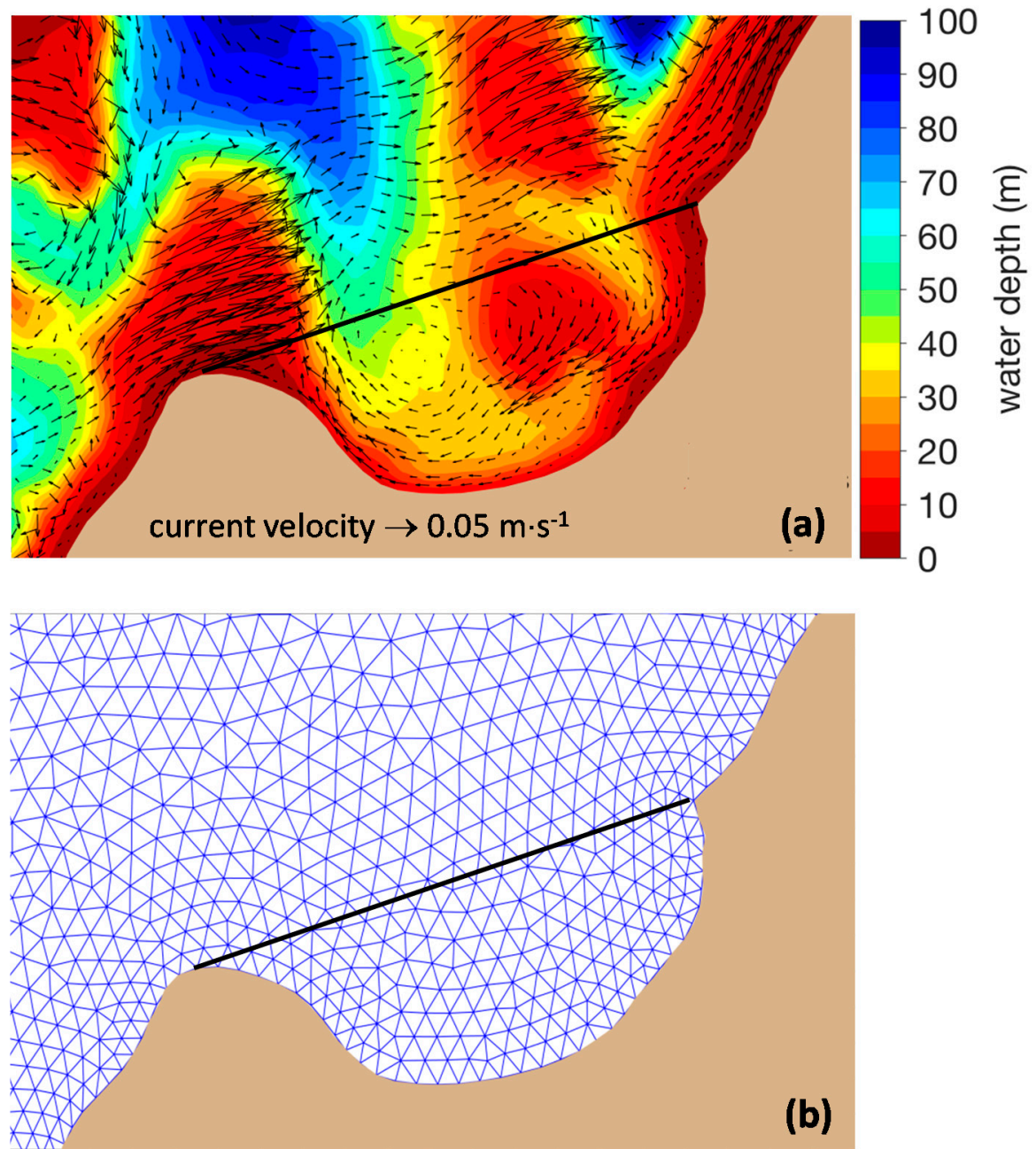

Figure 7. Physical conditions at Good Harbor Bay: (a) bathymetry and monthly average flow patterns (arrows) for July 2018; (b) FVCOM model grid. Black line in both panels defines the study system boundary. 
Due to the complexity of the flow pattern (Figure 7a), it is not sufficient to estimate cross-margin transport from one or several ADCP (Acoustic Doppler Current Profiler) observations of water velocity. It is more effective to calculate cross-boundary transport using a hydrodynamic model and test model performance using ADCP measurements. The Finite Volume Community Ocean Model (FVCOM) was applied here to determine cross-margin transport. FVCOM is a three-dimensional (3D), free-surface, primitive-equation hydrodynamic model that solves the integral form of the governing equations on an unstructured, sigma-coordinate mesh. The advantage of an unstructured grid mesh for shoreline fitting and local mesh refinement makes the model particularly attractive in applications to coastal waters. FVCOM has been applied in many coastal systems characterized by geometric complexities and highly variable flow patterns, including Lake Ontario [12,44] and Lake Michigan [29,45]. The particular version of the tool used here is the Lake Michigan-Huron FVCOM model, which supports the NOAA Lake Michigan-Huron Operational Forecast System (LMHOFS). The LMHOFS is driven by hourly data from High-Resolution Rapid Refresh (HRRR), a 3-km, cloud-resolving, and convection-allowing atmospheric model running in real time at the National Oceanic and Atmospheric Administration (NOAA) with radar data assimilated into the model at 15-min intervals [46]. The LMHOFS resolution varies from $2.5 \mathrm{~km}$ (coarse) in the offshore to $100 \mathrm{~m}$ (fine) in the targeted nearshore, adequately resolving the geographic complexity and coastal hydrodynamic conditions of the system (Figure 7b). Details regarding configuration and validation of FVCOM and LMHOFS skill assessments are provided by Peng et al. [47].

FVCOM was applied in calculating the mean daily cross-margin flow at Good Harbor Bay for the April-August period of 2016, 2017, and 2018; these results were then averaged to provide a representative cross-margin flow for the study system $\left(\mathrm{Q}=2.1 \times 10^{8} \mathrm{~m}^{3} \cdot \mathrm{d}^{-1}\right)$. Good Harbor Bay includes shallow nearshore water and shoal environments having light conditions favorable for Cladophora growth (0-10 m; [3]). Thus, in our biophysical model, we utilized the water volume and transport as calculated for the mean depth of $21 \mathrm{~m}$ normalized to a depth of $10 \mathrm{~m}$. Finally, we calculated cross-margin flow for 2018 at several other nearshore and embayment locations (Appendix A, Figure A1, Table A1) to facilitate comparison of conditions at Good Harbor Bay with other coastal environments. Cross-margin flows determined using FVCOM served as the hydrodynamic input to the biophysical model.

\subsection{Design and Execution of Numerical Experiments}

The modeling objective was to calculate concentrations of $\mathrm{SRP}_{\text {nearshore }}$ corresponding to a matrix of $\mathrm{PP}_{\text {offshore }}$ concentrations and mussel biomass densities (B) for specified values of $\mathrm{SRP}_{\text {offshore }}$ and cross-margin flow $(\mathrm{Q})$. Model calculations also required input of two biokinetic coefficients: $\mathrm{F}_{\mathrm{vol}}$, the mussel-specific filtration rate, and $f$, the coefficient for efficiency of mussel conversion of PP to SRP. Representative values and ranges for $\mathrm{F}_{\mathrm{vol}}, f$, and $\mathrm{B}$ were identified from the literature, for $\mathrm{Q}$ from FVCOM simulations (Appendix A, Table A1), and for PP and SRP in the nearshore and offshore from the U.S. EPA database (Appendix A, Table A2b,c). Inputs and coefficients supporting numerical experiments are summarized in Table 1.

Numerical experiments were performed to examine the sensitivity of $S R P_{\text {nearshore }}$ to values of $\mathrm{F}_{\mathrm{vol}}$ and $f$, to values of $\mathrm{Q}$, and to concentrations of SRP $\mathrm{P}_{\text {offshore. Next, numerical }}$ experiments were performed in a management context, first seeking to place pre- and post-dreissenid levels of $\mathrm{PP}_{\text {offshore }}$ and $\mathrm{SRP}_{\text {offshore }}$ on a two-dimensional map of model predicted $\mathrm{SRP}_{\text {nearshore }}$ concentrations for Good Harbor Bay. This result served to establish the likelihood that offshore P reserves could support nuisance levels of Cladophora growth at the study site. Finally, an approach was described where site-specific physical and biological mediating conditions may be quantified, extending model application broadly to coastal regions across the Great Lakes.

Numerical experiments consisted of applications of the linked hydrodynamic-biokinetic model, solving the mass balances for $\mathrm{PP}_{\text {nearshore }}$ (Equation (3a)) and $\mathrm{SRP}_{\text {nearshore }}$ (Equation (3b)) 
using a forward Euler method with a 0.1-day time step applied in Fortran 90. Each numerical experiment was run for 120 days, over which a steady state was reached, typically in $\sim 12$ days. Initial conditions are not relevant where a steady state is the desired endpoint.

\subsection{Interpreting the Results of Numerical Experiments}

The primary objective of this work was to quantify the potential for offshore reserves of SRP and PP to maintain nearshore SRP concentrations at levels sufficient to support nuisance growth of Cladophora in the absence of local sources of the nutrient. It has long been recognized that the relationship between Cladophora growth potential (growth rate, maximum biomass) and the nutritional status of the alga (stored P content) takes the form of a rectangular hyperbola [6,48-50]. We adopted the approach of Auer et al. [12], where the Great Lakes Cladophora Model (GLCM v3; [50]) was applied in developing a plot of normalized maximum attainable Cladophora biomass versus SRP concentration. Biomass increases in a linear fashion with increasing SRP concentration (region of $\mathrm{P}$ limitation), eventually transitioning to an asymptote where biomass accrual is insensitive to further increases in SRP (region of saturation). We adopted an SRP concentration of $1.25 \mathrm{mgP} \cdot \mathrm{m}^{-3}$, mid-range in the region of $\mathrm{P}$ limitation, as the criterion for avoidance of nuisance growth of Cladophora. In model output, we display the adopted criterion as a solid black line overlain on the SRP map at a concentration of $1.25 \mathrm{mgP} \cdot \mathrm{m}^{-3}$. We note that there is uncertainty with respect to the value identified for the adopted criterion (interpretation of the Cladophora biomass-SRP curve), input of the offshore SRP and PP concentrations (spatiotemporal variation, limit of detection), and the biophysical model (variability in biokinetic coefficients). These uncertainties are of lesser concern below the adopted criterion, as any position there is expected to avoid nuisance growth. Above the adopted criterion, however, uncertainties become more important as efforts to supplement phosphorus nutrition in offshore waters drives nearshore SRP concentrations toward those supporting nuisance conditions.

\section{Results and Discussion}

\subsection{Sensitivity Analysis}

The primary focus of our work was to characterize the potential for offshore reserves of SRP and PP, delivered to the nearshore through cross-margin transport, to maintain nearshore SRP concentrations at levels sufficient to support nuisance growth of Cladophora in the absence of local sources of the nutrient. We examined that potential across a matrix of offshore PP concentrations and mussel biomass densities, examining model sensitivity to the biokinetic parameters $\mathrm{F}_{\mathrm{vol}}$ and $f$, the rate of cross-margin transport and offshore SRP concentrations.

\subsubsection{Sensitivity to Biokinetic Coefficients}

In the biophysical model utilized here, biokinetic processes play a role in mediating levels of $\mathrm{SRP}_{\text {nearshore }}$ in two ways: first, with respect to the rate at which PP-containing water is entrained by mussels (filtration, $\mathrm{F}_{\mathrm{vol}}$ ), and second, by the efficiency with which that PP is converted to SRP $(f)$. Model sensitivity to values of $\mathrm{F}_{\mathrm{vol}}$ was examined for the lower quartile $\left(3.04 \mathrm{~m}^{3} \cdot \mathrm{mgAFDW}{ }^{-1} \cdot \mathrm{d}^{-1}\right)$, median $\left(4.75 \mathrm{~m}^{3} \cdot \mathrm{mgAFDW}^{-1} \cdot \mathrm{d}^{-1}\right.$; representative value), and upper quartile $\left(6.46 \times 10^{-4} \mathrm{~m}^{3} \cdot \mathrm{mgAFDW}^{-1} \cdot \mathrm{d}^{-1}\right)$ of selected results reported in the literature (Section 3.3; see Table 1). Values of $f$ applied in performing sensitivity analyses $(0.2,0.3,0.4$, and 0.5$)$ bracketed the representative value $(0.29)$ adopted from the literature in Section 3.2.1 (Section 3.3; see Table 1). Simulations were performed over ranges of $\mathrm{PP}_{\text {offshore }}$ and mussel biomass density with other model inputs ( $\mathrm{SRP}_{\text {offshore, }} \mathrm{Q}$, and $\mathrm{B}$ ) set at the representative values for Good Harbor Bay (Table 1).

Model-predicted concentrations of $\mathrm{SRP}_{\text {nearshore }}$ remained below the criterion concentration across the entire $\mathrm{F}_{\mathrm{vol}} \times f$ matrix (Figure 8). Of the two coefficients, model output was least sensitive to the value of $\mathrm{F}_{\mathrm{vol}}$, i.e., the map position for Good Harbor Bay (tri- 
angle, Figure 8) remained in essentially the same position relative to the criterion over the range of $\mathrm{F}_{\mathrm{vol}}$ values. The impact of variation in the value of $f$ was greater, with the gap in the Good Harbor map position and criterion concentration closing (but remaining within the criterion boundary) as $f$ increased. The first result, lack of sensitivity to $\mathrm{F}_{\mathrm{vol}}$, reflects the non-linearity and asymptotic behavior of biophysical forcing, as discussed subsequently (Section 4.3), while that of the second result points to increased lability of PP in mussel recycling.

\section{$\mathrm{SRP}_{\text {nearshore }}\left(\mathrm{mgP} \cdot \mathrm{m}^{-3}\right)$}

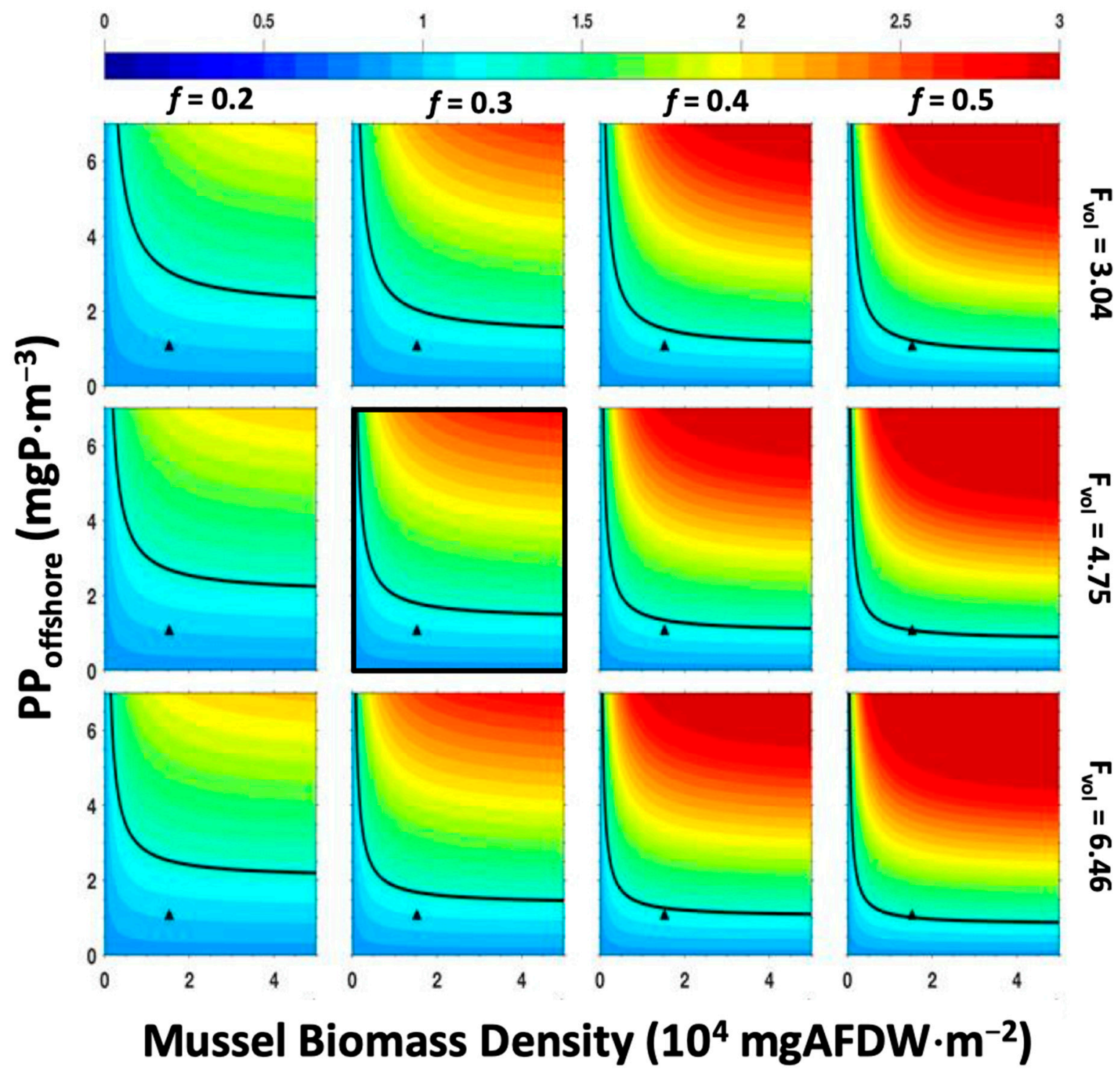

Figure 8. The sensitivity of model-predicted concentrations of $\mathrm{SRP}_{\text {nearshore }}$ to variation in the mussel filtration rate $\left(\mathrm{F}_{\mathrm{vol}}\right.$, $\left.\mathrm{m}^{3} \cdot \mathrm{mgAFDW} \mathrm{W}^{-1} \cdot \mathrm{d}^{-1}\right)$ and the mussel PP to SRP conversion efficiency ( $f$, dimensionless) mapped across a matrix of offshore PP concentrations ( $\left.\mathrm{PP}_{\text {offshore}}\right)$ and mussel biomass densities (B). The solid black line represents the adopted criterion for $\mathrm{SRP}_{\text {nearshore}}$, i.e., the concentration below which nuisance growth of Cladophora is not anticipated. The triangles locate conditions of $\mathrm{SRP}_{\text {nearshore }}$ at Good Harbor Bay based on $\mathrm{SRP}_{\text {offshore }}, \mathrm{PP}_{\text {offshore, }}$ and $\mathrm{B}$ calculated for Lake Michigan in the post-dreissenid period (Table 1). The panel outlined in bold represents results for conditions at Good Harbor Bay. Note that

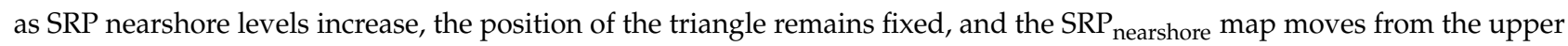
right to lower left. 


\subsubsection{Sensitivity to the Rate of Cross-Margin Transport}

The degree to which offshore forcing serves to mediate nuisance Cladophora growth is, in part, influenced by the rate of cross-margin transport (Q). In this sensitivity analysis, we explored the impact of variability in that rate over a range of cross-margin flows $\left(\mathrm{Q}=0.25-6 \times 10^{8} \mathrm{~m}^{3} \cdot \mathrm{d}^{-1}\right)$ representing two reaches of near-linear Lake Michigan shoreline and two of the lake's embayments (Appendix A, Table A1). Ranges for $\mathrm{PP}_{\text {offshore }}$ and $\mathrm{B}$ were as for the previous scenario, and values for other model inputs and coefficients were those presented as representative values in Table 1 . We also included a new metric $\left(\mathrm{Q}_{\text {mussels }}, \%\right)$, calculated as the ratio of mussel filtration $\left(\mathrm{F}_{\mathrm{vol}} \cdot \mathrm{B}, \mathrm{m}^{3} \cdot \mathrm{d}^{-1}\right)$ calculated and expressed as a percentage of $\mathrm{Q}$.

In these simulations, representing diverse shoreline structure, model-predicted $\mathrm{SRP}_{\text {nearshore }}$ concentrations remained below the adopted criterion for avoidance of nuisance growth of Cladophora (Figure 9). In essence, this simulation portrays a dilution series. The dilution effect is evident in the opening of the gap between the Good Harbor Bay map position and the criterion concentration as $Q$ increases (Figure 9). Here, mussels were processing a lesser fraction of the cross-margin supply, and the nearshore waters came more to resemble offshore conditions. The rate of cross-margin flow, determined for Good Harbor Bay using FVCOM $\left(\mathrm{Q}=2.1 \mathrm{x} \times 10^{8} \mathrm{~m}^{3} \cdot \mathrm{d}^{-1}\right.$; Section 3.3, Table 1$)$, was carried forward as the representative value for further simulations.

\subsubsection{Sensitivity to Offshore SRP Concentration}

Forcing of $\mathrm{SRP}_{\text {nearshore }}$ by offshore reserves is of particular interest in a management context because the SRP analyte is the form of the nutrient freely and fully available to support Cladophora growth. In examining the sensitivity of $\mathrm{SRP}_{\text {nearshore }}$ to cross-margin transport, we examined SRP ${ }_{\text {offshore }}$ concentrations of $0.5,0.8,1.0,1.25$, and $1.5 \mathrm{mgP} \cdot \mathrm{m}^{-3}$. The lowest value, $0.5 \mathrm{mgP} \cdot \mathrm{m}^{-3}$, is below the representative value for the offshore waters of Lake Michigan (Table 1) in the pre- and post-dreissenid periods and approximates the detection limit for the analyte. The value $0.8 \mathrm{mgP} \cdot \mathrm{m}^{-3}$ approximates that considered a representative value for the offshore waters of Lake Michigan in the pre- and postdreissenid Periods (Table 1). Values of $1.0,1.25$, and $1.5 \mathrm{mgP} \cdot \mathrm{m}^{-3}$ represent the linear, P-limited range of Cladophora growth, with $1.25 \mathrm{mgP} \cdot \mathrm{m}^{-3}$ being the adopted criterion for avoidance of nuisance growth. Concentrations beyond this range correspond to Psaturated conditions, levels experienced at times in Lakes Michigan (and regularly in Lake Ontario; [9]) in the pre-dreissenid period.

Simulation results, presented here as Figure 10, indicate that concentrations of $S R P_{\text {nearshore }}$ will remain below the adopted SRP criterion of $1.25 \mathrm{mgP} \cdot \mathrm{m}^{-3}$ for SRP offshore concentrations $<1 \mathrm{mgP} \cdot \mathrm{m}^{-3}$ and a $\mathrm{PP}_{\text {offshore }}$ concentration $1.05 \mathrm{mgP} \cdot \mathrm{m}^{-3}$, the median value for the post-dreissenid period (Table 1). At an SRP concentration of $1.25 \mathrm{mgP} \cdot \mathrm{m}^{-3}, \mathrm{SRP}_{\text {nearshore }}$ will, by definition, be greater than or equal to the adopted criterion, exceeding that value through conversion of PP to SRP. At SRP offshore levels exceeding $1.25 \mathrm{mgP} \cdot \mathrm{m}^{-3}$, the adopted criterion will be exceeded at all combinations of $\mathrm{PP}_{\text {offshore }}$ and mussel biomass density, and the system becomes whole-lake forced. These simulation results indicate that nuisance growth of Cladophora will not be supported where $\mathrm{SRP}_{\text {offshore }}$ and $\mathrm{PP}_{\text {offshore }}$ concentrations both remain $\leq 1 \mathrm{mgP} \cdot \mathrm{m}^{-3}$, i.e., a condition consistent with contemporary (post-dreissenid) levels (Table 1). 


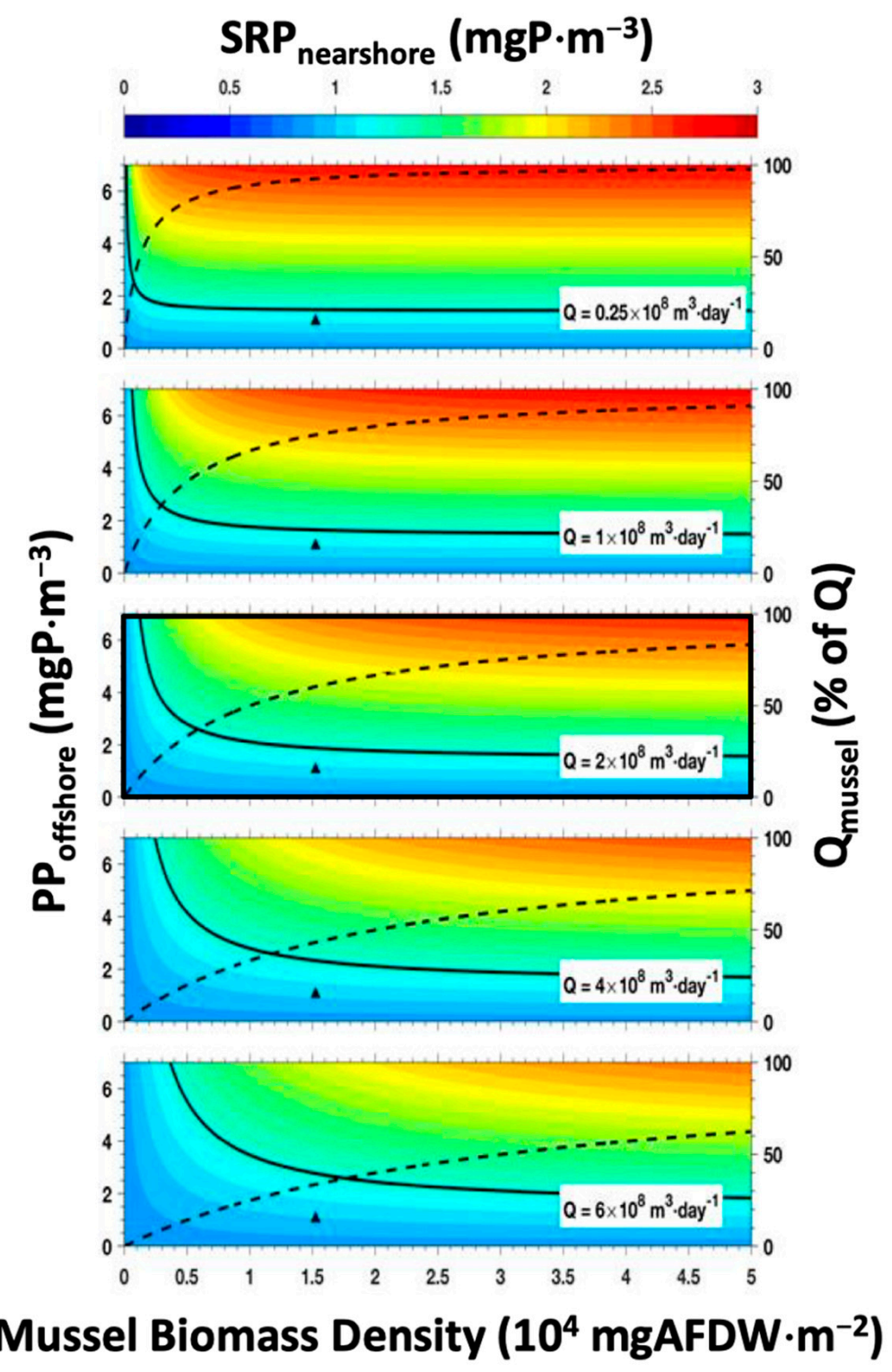

Figure 9. The sensitivity of model-predicted concentrations of $\mathrm{SRP}_{\text {nearshore }}$ to variation in the rate of cross-margin flow $(\mathrm{Q})$ mapped across a matrix of offshore PP concentrations ( $\left(\mathrm{PP}_{\text {offshore }}\right)$ and mussel biomass densities (B). The solid black line represents the adopted criterion for SRP $\mathrm{nearshore}_{\text {, }}$ i.e., the concentration below which nuisance growth of Cladophora is not anticipated. The dashed black line represents the percentage of the cross-margin flow entrained by mussels $\left(Q_{\text {mussels }}\right)$. The triangles locate conditions of $\mathrm{SRP}$ nearshore at Good Harbor Bay based on $\mathrm{SRP}_{\text {offshore }}, \mathrm{PP}_{\text {offshore, }}$ and $\mathrm{B}$ calculated for Lake Michigan in the post-dreissenid period (Table 1). The panel outlined in bold represents results for conditions at Good Harbor Bay. Note that as SRP nearshore levels increase, the position of the triangle remains fixed, and the $\mathrm{SRP}_{\text {nearshore }}$ map moves from the upper right to lower left. 


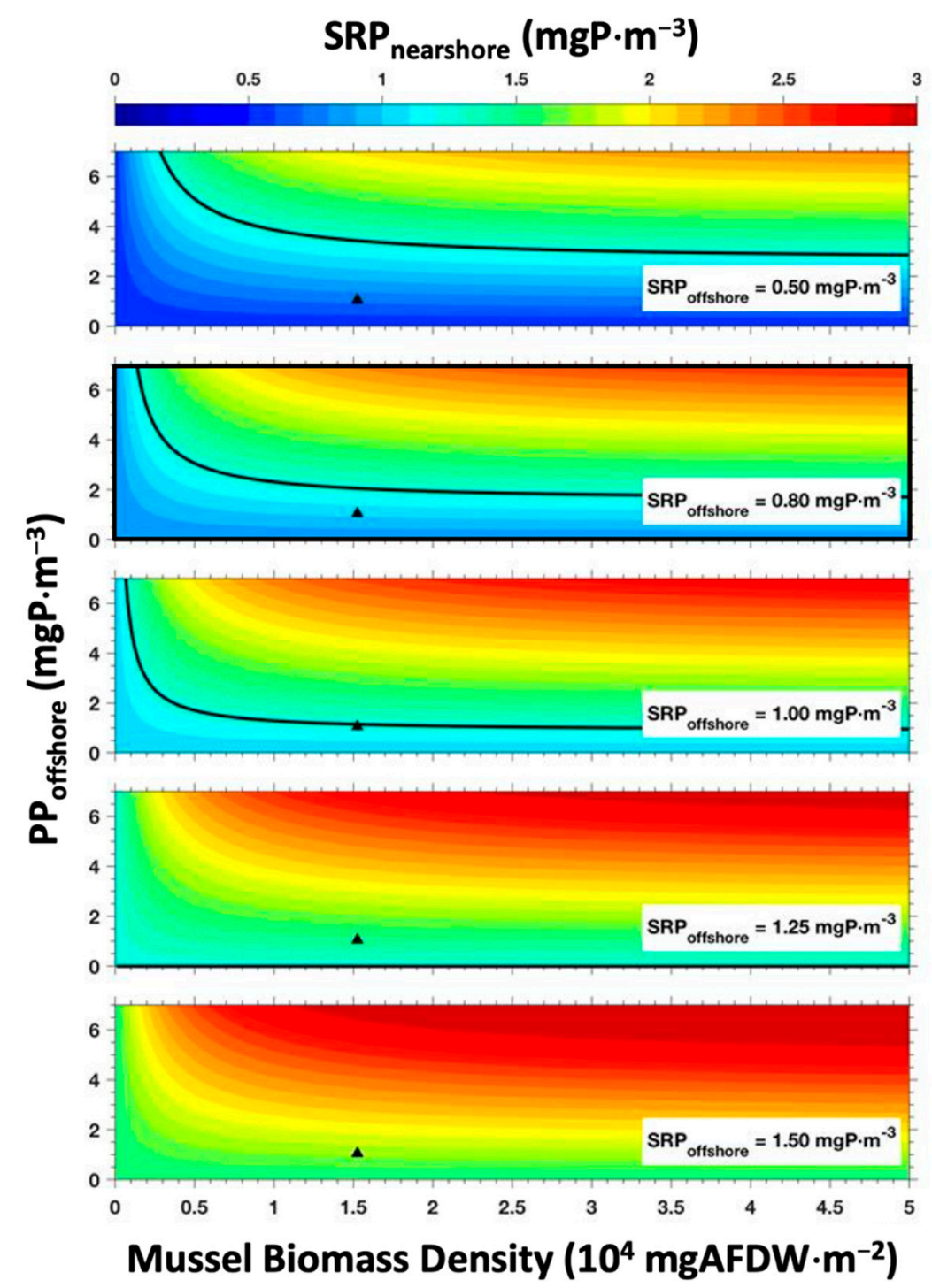

Figure 10. The sensitivity of model-predicted concentrations of SRP nearshore to variation in the concentration of $\mathrm{SRP}_{\text {offshore }}$ mapped across a matrix of offshore $\mathrm{PP}$ concentrations $\left(\mathrm{PP}_{\text {offshore }}\right)$ and mussel biomass densities (B). The solid black line represents the adopted criterion for SRP nearshore i.e., the concentration below which nuisance growth of Cladophora is not anticipated. The triangles locate conditions of $\mathrm{SRP}_{\text {nearshore }}$ at Good Harbor Bay based on $\mathrm{SRP}_{\text {offshore }}, \mathrm{PP}_{\text {offshore, }}$ and $\mathrm{B}$ calculated for Lake Michigan in the post-dreissenid period (Table 1). The panel outlined in bold represents results for conditions at Good Harbor Bay. Note that as SRP nearshore levels increase, the position of

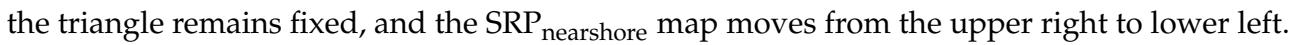

\subsection{Management Analysis for Good Harbor Bay}

The biophysical model was then applied to examine management considerations relating to offshore forcing of nuisance growth of Cladophora at Good Harbor Bay. Model inputs and coefficients were those applied to and derived from sensitivity analyses (Table 1). The biophysical model generates a two-dimensional map of SRP nearshore concentrations for ranges of $\mathrm{SRP}_{\text {offshore }}$ and $\mathrm{PP}_{\text {offshore }}$ (Figure 11). The position of the Good Harbor Bay environment on the SRP nearshore map was identified for the post-dreissenid period (Table 1), evaluated with respect to the adopted $S R P_{\text {nearshore }}$ criterion and placed in a management context by comparing conditions forced solely by offshore SRP and PP reserves with those forced locally. Simulation results for the post-dreissenid period indicated that nearshore waters, forced solely by offshore PP and SRP levels, would 
be P-limited and essentially consistent with the objective of the SRP adopted criterion (Figure 11).

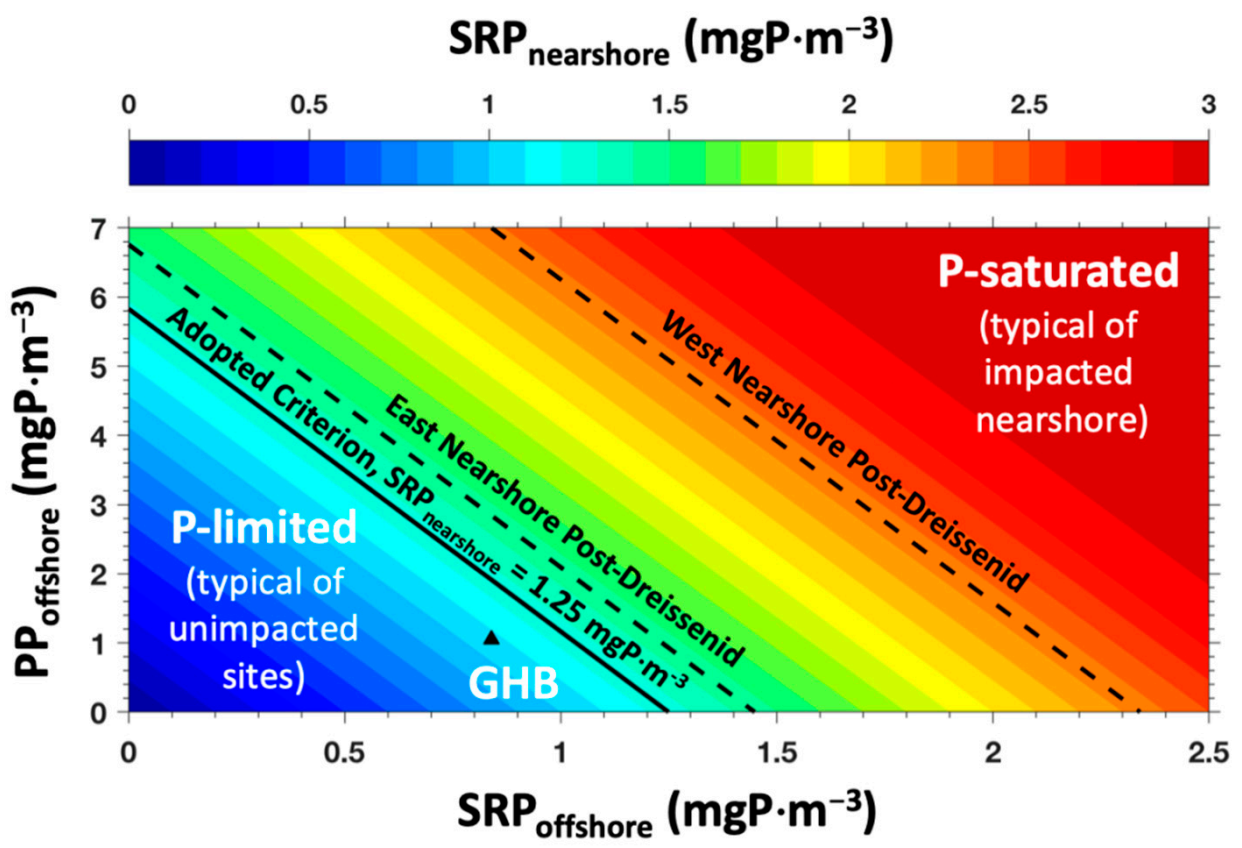

Figure 11. A map of model-predicted $S R P_{\text {nearshore }}$ concentrations, with the adopted $S R P_{\text {nearshore }}$ criterion for eliminating nuisance growth of Cladophora (solid line) dividing the map into P-limited (below the line) and P-saturated (above the line) regions. The map position corresponding to sole forcing of $\mathrm{SRP}_{\text {nearshore }}$ by offshore sources is identified for the post-dreissenid period by a black triangle. As a point of reference, SRP concentrations measured for the east and west nearshore in the post-dreissenid period (Table 1 ) are also positioned on the $S R P_{\text {nearshore }}$ map.

The results presented as Figure 11 provide a map of model calculated $\mathrm{SRP}_{\text {nearshore }}$ concentrations corresponding to sole source forcing by offshore SRP and PP reserves, i.e., in the absence of local discharges to nearshore waters. It is not appropriate to apply our 0-D steady-state biophysical model in simulating nearshore conditions influenced by local forcing. This is due to the heterogeneity inherent in discharge plumes attributable to the complexity of coastal hydrodynamics and the placement and timing of inputs. It is, however, appropriate (and useful) to identify the map position of nearshore waters relative to the adopted criterion (Figure 11) as reflected in measurements of SRP ${ }_{\text {nearshore }}$ (Table 1d). This result shows that $S R P_{\text {nearshore }}$ concentrations along the east coast of Lake Michigan (lower landscape activity) would lie beyond the adopted criterion for $\mathrm{SRP}_{\text {nearshore }}$ even with a reasonable uncertainty in the boundary between P-limited and P-saturated conditions. Concentrations of SRP nearshore along the west coast lie far beyond the criterion boundary, likely reflecting higher levels of landscape activity.

\subsection{Extending the Model Application}

The map of $\mathrm{SRP}_{\text {nearshore, }}$ presented previously as Figure 11, serves well in illustrating several points relating to offshore forcing and the Dual Challenge. However, its application as a more general-purpose tool is limited, as it accommodates only the intrinsic representative values for mussel biokinetics $\left(\mathrm{F}_{\mathrm{vol}}, f\right)$ selected here and the site-specific conditions of cross-margin transport (Q) and mussel biomass density (B) for Good Harbor Bay. To provide a more broadly applicable and user-friendly tool, we developed algorithms for determination of conditions satisfying the adopted criterion for various combinations of 
those inputs and coefficients. This is accomplished by introducing a term, the biophysical coefficient $(\alpha)$, defined mathematically as

$$
\alpha=\frac{\mathrm{F}_{\mathrm{vol}} \cdot \mathrm{B}}{\mathrm{H}} \cdot \tau
$$

where $\tau$ is the water residence time (days) in an embayment or coastal segment. The R.H.S of Equation (13) can be rewritten as

$$
\alpha=\frac{\mathrm{F}_{\mathrm{vol}} \cdot \mathrm{B}}{\mathrm{H}} /\left(\frac{1}{\tau}\right)
$$

which reflects the complementary or competitive role of biological $\left(\mathrm{F}_{\mathrm{vol}} \cdot \mathrm{B} / \mathrm{H}\right)$ and physical $(1 / \tau)$ processes in determining the value of $\alpha$. For example, a site with high mussel biomass densities (B) and a low flushing rate (extended residence time) would reflect a case where biophysical processes act in a complementary fashion to increase the value of $\alpha$ and thus the potential for nuisance growth of Cladophora. On the other hand, a site with high mussel biomass densities but experiencing a high flushing rate (limited residence time) would serve as an example of competition between biophysical processes resulting in a lower value of $\alpha$ and a lower potential for nuisance growth.

In this derivation, $\alpha$ is embedded in a parenthetical term referred to as the biophysical influence factor, $I F=\left(1-\frac{1}{1+\alpha}\right) \cdot 100 \%$, quantifying the percentage of the $\mathrm{PP}_{\text {offshore }}$ delivered to the nearshore by cross-margin transport converted to SRP. Substituting $\alpha$ to the governing equations of the nearshore P-mussel model (Equations (6a) and (6b)), a steady-state solution for $\mathrm{SRP}_{\text {nearshore }}$ can be developed as

$$
\mathrm{SRP}_{\text {nearshore }}=\mathrm{SRP}_{\text {offshore }}+I F \cdot f \cdot \mathrm{PP}_{\text {offshore }}
$$

Mathematically, $\alpha$ could range from 0 to positive infinity $\left(\infty^{+}\right)$, and the influence factor (IF) would vary between $0 \%$ and $100 \%$ (Figure 12). For $\alpha \rightarrow 0$, the influence factor $\rightarrow$ $0 \%$, and $\mathrm{SRP}_{\text {nearshore }}$ would $\rightarrow \mathrm{SRP}_{\text {offshore, }}$ its lower limit. At the other extreme, $\infty^{+}$, the influence factor $\rightarrow 100 \%$, and $\mathrm{SRP}_{\text {nearshore }} \rightarrow \mathrm{SRP}_{\text {offshore }}+f \cdot \mathrm{PP}_{\text {offshore, }}$ its upper limit. The

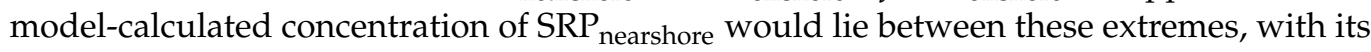
position depending on the value of IF as mediated by $\alpha$, i.e., local biophysical conditions (Equation (15)). The significance of this solution lies in the fact that, for any given set of boundary conditions (the open-lake properties $\mathrm{SRP}_{\text {offshore }}$ and $\mathrm{PP}_{\text {offshore }}$ ), the intrinsic processes of mussels $\left(f\right.$ and $\mathrm{F}_{\mathrm{vol}}$ ) and site-specific values of $\mathrm{B}, \mathrm{H}$, and $\tau$, concentrations of

\begin{tabular}{|c|c|c|c|c|c|c|}
\hline $\begin{array}{c}\text { Site on } \\
\text { Lake Michigan }\end{array}$ & $\begin{array}{c}\mathbf{H} \\
(\mathrm{m})\end{array}$ & $\begin{array}{c}\tau \\
\text { (Days) }\end{array}$ & $\begin{array}{c}\text { B } \\
\text { Contemporary } \\
\left(\mathrm{mgAFDW} \cdot \mathrm{m}^{-2}\right)\end{array}$ & $\begin{array}{c}\alpha \\
\text { Contemporary } \\
\text { (Dimensionless) }\end{array}$ & $\begin{array}{c}\text { B } \\
\text { No Local P } \\
\text { Sources } \\
\left(\mathrm{mgAFDW} \cdot \mathrm{m}^{-2}\right)\end{array}$ & $\begin{array}{c}\alpha \\
\text { No Local P } \\
\text { Sources } \\
\text { (Dimensionless) }\end{array}$ \\
\hline Good Harbor Bay & 10 & 4.47 & $\begin{array}{c}15,266 \\
{[21,23,25]}\end{array}$ & 3.24 & 10,069 & 2.13 \\
\hline $\begin{array}{c}\text { Milwaukee, WI } \\
\text { nearshore region }\end{array}$ & 13.03 & 5.44 & $\begin{array}{c}98,560 \\
{[15]}\end{array}$ & 19.55 & 10,069 & 2.00 \\
\hline Big Bay De Noc & 7.63 & 15.3 & $\begin{array}{l}4510 \\
{[24]}\end{array}$ & 4.29 & 10,069 & 9.59 \\
\hline $\begin{array}{c}\text { Southeast } \\
\text { nearshore region }\end{array}$ & 12.29 & 7.48 & $\begin{array}{c}10,431 \\
{[24]}\end{array}$ & 3.01 & 10,069 & 2.91 \\
\hline
\end{tabular}
$\mathrm{SRP}_{\text {nearshore }}$ can be estimated at any location.

Table 2. Coefficients and inputs used to calculate the value of $\alpha$ for four selected regions on Lake Michigan. 
(a)
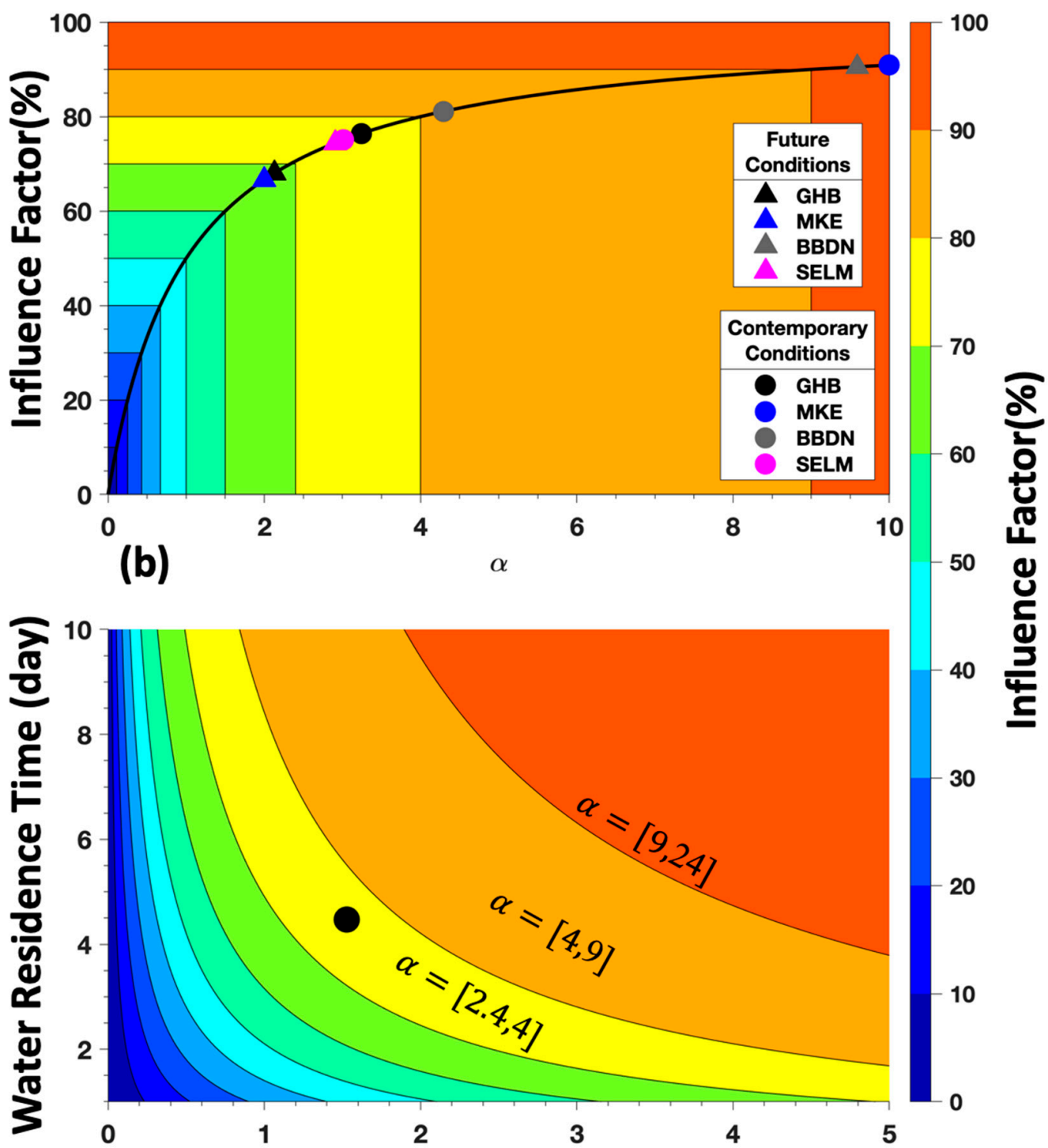

Mussel Biomass Density $\left(10^{4} \mathrm{mgAFDW} \cdot \mathrm{m}^{-2}\right)$

Figure 12. Model simulation of the relationship between (a) the coefficient $\alpha$ and the biophysical influence factor IF as developed in Equations (14) and (15); (b) between $\alpha$ and IF and their biological (mussel biomass density) and physical (water residence time) forcing conditions. Model inputs and coefficients for this simulation are those for Good Harbor Bay (Tables 1 and 2). Colored areas in both panels demarcate ranges in IF having different slopes ( $\Delta \mathrm{IF} / \Delta \alpha$, the black line) and thus different sensitivity to changes in biophysical forcing. In (a), dots represent values of $\alpha$ calculated for contemporary conditions of mussel biomass density (intersite variability), and triangles represent future conditions, i.e., the average of biomass density for the three sites largely unimpacted by local sources (BBDN, GHB, and SELM). The black dot in (b) represents the position of GHB within the region insensitive to variability in biophysical conditions.

The nonlinear nature of the $\alpha-I F$ relationship (Figure 12a) is such that IF increases rapidly with $\alpha$ when $\alpha$ is small (e.g., $\alpha=(0,2.4)$ corresponds to $I F=(0 \%, 70 \%))$ and less rapidly and asymptotically approaching a value of $100 \%$ when $\alpha$ is large (e.g., $\alpha=\left(4, \infty^{+}\right)$corresponds to $\left.I F=(80 \%, 100 \%)\right)$. This suggests that the value of $I F$ may be insensitive to changes in $\tau$ and B for values of $\alpha>2.4$ and certainly insensitive for $\alpha>4$ (Figure 12b). This is illustrated for Good Harbor Bay (black dots in Figure 12a,b) by 
examining the $I F$ response to variation in $\tau$ about its representative value ( $4.47 \pm 1.5$ days). The resulting change in IF (68-81\%) is only $13 \%$ because Good Harbor Bay lies in the insensitive region. Similarly, the response for a change in B about its representative value $(15,266 \pm 5000) \mathrm{mgAFDW} \cdot \mathrm{m}^{-2}$ would result in only a change of $12 \%(69 \%-81 \%)$, again, because Good Harbor Bay lies in the insensitive region.

Next, we extended the application of the model to three additional sites on Lake Michigan, yielding a total of four study locations: two embayments (Good Harbor Bay, MI, GHB and Big Bay De Noc, MI, BBDN) and two near-linear coastal segments (the nearshore at Milwaukee, WI, MKE and a segment of the southeast coastline, MI, SELM) (Appendix A, Figure A2). The coefficient $\alpha$ was calculated using Equation (14) and site-specific values for $\mathrm{H}$ (depth, influencing water-column dilution of mussel SRP excretion), B (mussel biomass density, influencing PP processing capacity), and $\tau$ (residence time, influencing flushing of the nearshore) (Appendix A1, Tables 2 and A1). Simulation results are presented for each location (dots in Figure 12a) applying site-specific values of $\mathrm{H}$ and $\tau$ (invariant in time) and values of $B$ representing contemporary levels of food supply (i.e., prior to any local $\mathrm{P}$ source remediation). All of the stations fall within the insensitive region of the $\alpha$-IF plot, yielding IF values ranging from $70 \%$ to $100 \%$ (yellow, orange, and red) and indicating that variability in B would only modestly influence the impact factor.

We note, however, that $\alpha$ is defined for equilibrium conditions, i.e., that mussel biomass densities are in equilibrium with the contemporary mussel food supply. Changes in nearshore conditions, such as reductions in point-source effluent $\mathrm{P}$ levels, would alter mussel food source concentrations, lead to an increase in mussel mortality, and result in a new equilibrium condition with different values for $\alpha$ and IF. We tested this consideration by running the model at a level of $B\left(10,069 \mathrm{mgAFDW} \cdot \mathrm{m}^{-2}\right)$ calculated as the simple average for densities measured at sites apparently unimpacted by local inputs (GHB, SELM, and BBDN). The results indicate that all four locations (Figure 12a, triangles) would remain within the IF-insensitive region for levels of $B$ characteristic of locations unimpacted by local sources. There is a small incursion into the transition region for GHB and MKE, but the magnitude of this effect is with the tolerances of the regional definitions. We conclude from these simulations that model inputs of B may be equally well represented by biomass densities at local source-driven sites or those estimated for unimpacted sites.

Having addressed the issue of intersite variability in biophysical factors, we turned to the management implications of our findings with respect to offshore forcing of Cladophora growth in the absence of local sources and to a management approach for meeting the objectives of the nearshore endmember of the Dual Challenge. First, we examined modelpredicted concentrations of $S R P_{\text {nearshore }}$ at the four sites identified previously. Simulation results take the form of a 2-D map of $S R P_{\text {nearshore (Figure 13a) with the biokinetic coefficients }}$ $\mathrm{F}_{\mathrm{vol}}$ and $f$ as in Table 1a and site-specific inputs $(\mathrm{H}, \tau$, and B), as in Table 2. SRP nearshore (triangles and lower and upper bars in Figure 13a) was simulated for the median $\mathrm{SRP}_{\text {offshore }}$ concentration $\left(0.84 \mathrm{mgP} \cdot \mathrm{m}^{-3}\right.$; Table $\left.1 \mathrm{~b}\right)$ and the median $\left(1.05 \mathrm{mgP} \cdot \mathrm{m}^{-3}\right.$; Table $\left.1 \mathrm{~b}\right)$ and lower and upper quartile concentrations $\left(0.6\right.$ and $1.6 \mathrm{mgP} \cdot \mathrm{m}^{-3}$; Figure $\left.6 \mathrm{~b}\right)$ of $\mathrm{PP}_{\text {offshore. }}$ The black line represents the adopted criterion for elimination of nuisance growth of Cladophora. The results of these simulations (median and quartile positions in Figure 13a) affirm the finding presented above that variability in biophysical conditions (as reflected in $\alpha$ ) will not influence the magnitude of $\mathrm{SRP}_{\text {nearshore }}$ (Figure 13a). Thus, simulations using Equations (6a) and (6b) or the simplified form presented as Equation (15) and drawing on inputs developed for Good Harbor Bay and the offshore waters of Lake Michigan (Tables 1 and 2) will yield credible results for all sites on Lake Michigan (and potentially across the Great Lakes). Of particular importance is the key finding that concentrations of SRP nearshore remain below the adopted standard for all cases, indicating that none of the sites would be expected to experience nuisance conditions of Cladophora growth solely through offshore forcing. 


\section{(a)}

\section{$\mathrm{SRP}_{\text {nearshore }}\left(\mathrm{mgP} \cdot \mathrm{m}^{-3}\right)$}

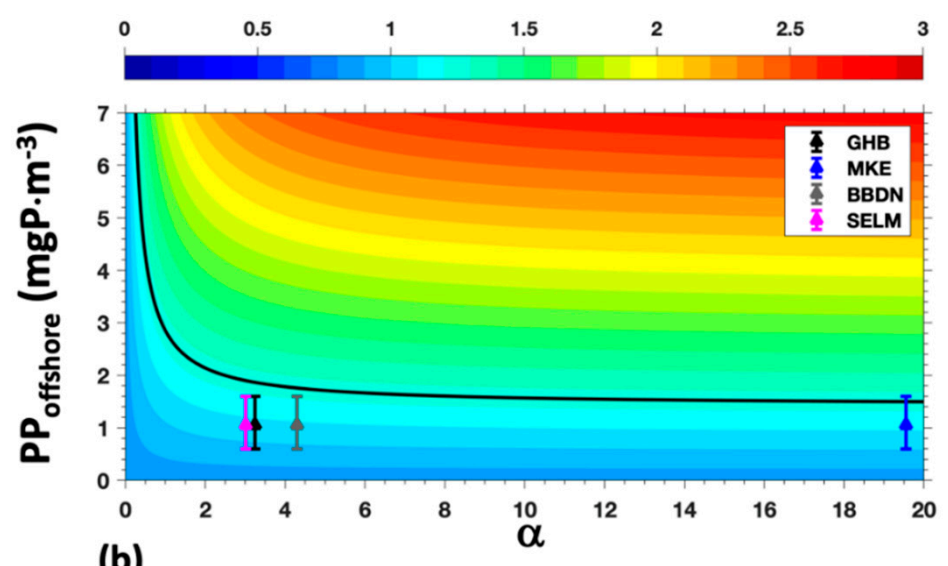

(b)

$\mathrm{SRP}_{\text {nearshore }}\left(\mathrm{mgP} \cdot \mathrm{m}^{-3}\right)$

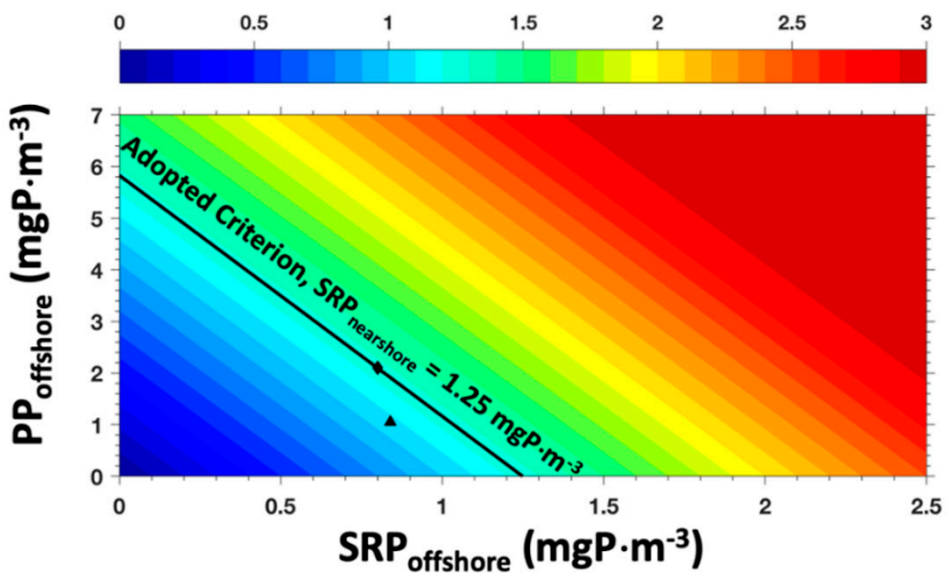

Figure 13. Management insights derived from this analysis: (a) sensitivity to variation in biophysical forcing conditions at four locations on Lake Michigan: Big Bay de Noc, MI (BBDN); Good Harbor Bay, MI (GHB); a southeast coastal segment, MI (SELM); and the Milwaukee, WI nearshore (MKE); (b) nearshore SRP levels at Good Harbor Bay for pre- and post-dreissenid conditions, illustrating a management approach where a return to pre-dreissenid SRP concentrations in the nearshore could offer nutrient supplementation to the offshore without stimulating nuisance growth of Cladophora.

The finding that, absent local sources, the Lake Michigan nearshore would not support nuisance growth solely through offshore forcing suggests that there is a margin available for use in supplementing offshore nutrient conditions to benefit the food web. To explore

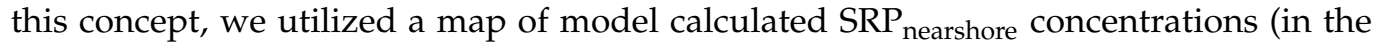
spirit of Figure 11) corresponding to sole-source forcing by offshore reserves of SRP and PP

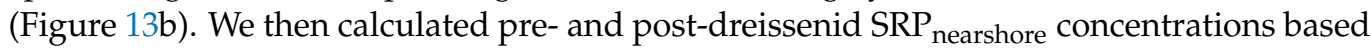
on the corresponding pre- and post-dreissenid offshore SRP and PP levels (Table 1b,c). The

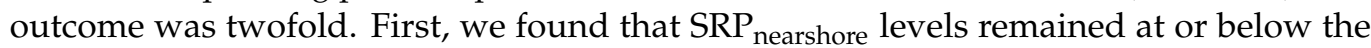
adopted threshold for nuisance Cladophora growth in both the pre- and post-dreissenid periods. Second, the difference in $\mathrm{SRP}_{\text {nearshore }}$ between the pre- $\left(2.10 \mathrm{mgP} \cdot \mathrm{m}^{-3}\right)$ and post$\left(1.05 \mathrm{mgP} \cdot \mathrm{m}^{-3}\right)$ dreissenid periods may reflect the change in trophic-state, causing food web disruption and thus the margin available to supplement offshore phosphorus reserves without engendering nuisance Cladophora growth in the nearshore. 


\section{Cross-Margin Transport in a Management Context}

The research results presented here have sought to address questions relating to the efficacy and consequences of implementing a higher level of phosphorus removal for point-source discharges to the Lake Michigan nearshore. The efficacy question proceeds from the premise that nuisance levels of Cladophora growth could be sustained by crossmargin, offshore to nearshore transport of SRP and PP, even following implementation of P-reduction strategies at wastewater-treatment facilities and management of nonpoint sources. The work of Waples and Klump [51] contributed significantly to development of this train of thought, reporting that cross-margin transport of particulate matter was an order of magnitude greater than vertical water-column fluxes and exceeded estimates of terrigenous flux.

Subsequently, Waples et al. [52] noted that the mussel organic carbon demand in the nearshore exceeded that of pelagic primary production by several fold and that two-thirds of the vertical particulate organic carbon flux to the nearshore benthos was sourced from the offshore, with the remaining one-third produced locally. The authors thus concluded that if mussels are fed by particulate organic matter produced in the water column, then local demand must be supplemented by lateral (cross-margin) transport. Based on these findings, it is reasonable to conclude that if offshore waters are the dominant food source for mussels, then a significant portion of the attendant mussel phosphorus excretion flux may also be attributed to the particulate phosphorus provided through cross-margin transport. From this evolves the efficacy concern and the first research question: Can offshore reserves of particulate matter (PP) support nuisance growth of Cladophora in the nearshore in the absence of local sources of the nutrient?

The consequences concern changes the question from one of offshore waters supplementing nearshore phosphorus reserves to that of nearshore phosphorus providing a source for food web production in the offshore. Shen et al. [17] applied a biophysical model to examine the influence of mussels on phosphorus cycling in Lake Michigan. Their results pointed to a lake-wide reduction in the particulate to dissolved phosphorus ratio, evidence of a lesser amount of food available at the base of the food chain. The nearshore was identified as a net source of particulate phosphorus to the offshore, raising the concern that mussel activity could reduce PP levels in the nearshore and thus the supply to the offshore, negatively impacting both the lower and upper food web. The consequences concerned has been recognized and incorporated into what has been termed the Dual Challenge [18], balancing the management of phosphorus stimulation in the nearshore while sustaining commercial, recreational, and native fish populations. Our second research question then becomes: How can this balance be achieved?

In this paper, we applied a biophysical model in seeking insights regarding the "efficacy" and "consequences" research questions. The biophysical model contains a biological component simulating rates of mussel PP acquisition and SRP excretion and a physical component simulating the rate of cross-margin transport. Implementation of the biological component requires specification of SRP and PP concentrations in offshore waters and mussel biomass densities in the nearshore. Representative values for these inputs were established from online databases (U.S. EPA GLENDA and USGS). The biological component also requires specification of two kinetic coefficients: the mussel volumetric filtration rate, and the conversion efficiency for PP to SRP in mussel recycling. These coefficients were determined through a review of the literature and a comparison of representative coefficient values to measured rates. The physical component, FVCOM, is driven by meteorological forcing conditions and has been performance tested by our group at sites across the Great Lakes $[12,44,53-56]$. Output from the biophysical model may be portrayed as a map of SRP concentrations in the nearshore as a function of offshore SRP and PP levels for representative values of the biophysical inputs and coefficients described above. Various combinations of offshore SRP and TP may be placed on the nearshore SRP map to compare contemporary or forecast conditions with an adopted criterion for preventing nuisance Cladophora growth. Simulations were performed here for Good Harbor 
Bay and then extended to three additional locations on Lake Michigan, resulting in two segments of near-linear shoreline and two embayments. Having conducted this study, we make the following summary observations:

The Efficacy Question. Can offshore reserves of soluble, reactive, and particulate phosphorus support nuisance growth of Cladophora in the absence of local sources of the nutrient?

1. In the absence of local sources of phosphorus, rates of Cladophora growth and biomass accrual are controlled by cross-margin transport of the nutrient from offshore to nearshore waters. The development of Cladophora beds and attendant beach accumulation will, in the absence of local sources, vary with the concentrations of SRP and PP in the open lake, i.e., the lake's trophic status.

2. The potential for offshore stimulation of nuisance conditions on Lake Michigan was examined at Good Harbor Bay, a location absent local forcing. Simulations were performed for representative offshore concentrations of SRP and PP and other model inputs and coefficients. The results indicate that offshore forcing would not support SRP concentrations in the Good Harbor Bay nearshore sufficient to cause nuisance conditions. We posit that observations of accumulating algal debris in water adjoining Good Harbor Bay (e.g., Sleeping Bear Dunes National Lakeshore) reflects habitat expansion due to water-column clearing by mussels.

3. The analysis was extended beyond Good Harbor Bay to three additional locations on Lake Michigan to examine the sensitivity of nearshore SRP levels to variability in physical (cross-margin transport, flushing time) and biological (mussel biomass) forcing. Model projections indicate that nearshore SRP levels are insensitive to these factors for these four sites and that results evolving from analysis of conditions at Good Harbor Bay are applicable lake wide.

In conclusion, we return to our initial point. Offshore levels of SRP and PP mediate rates of Cladophora growth and biomass accrual in the absence of local sources. In addition, while colonization of solid substrate by Cladophora is almost ubiquitous across the nearshore waters of Lakes Michigan, Huron, and Ontario, the occurrence of nuisance conditions is not. This observation and the results of our offshore forcing analysis in Lake Michigan resonate with the conclusion of Higgins et al. [7] that, in Lake Ontario, there was little evidence that $\mathrm{P}$ from metabolic waste products of dreissenid mussels was sufficient to produce severe Cladophora blooms in the absence of localized P enrichment. The association of severe blooms of the alga with local P sources has been demonstrated for Lake Michigan (e.g., [19]) and evidenced in the regional effect of local P sources, with higher SRP and PP concentrations along the west shore of the lake than along the east shore (data of Yurista et al. [43]), a result ascribed to differences in landscape activity. We thus support the recommendation made by Higgins et al. [7] that effective management of Cladophora blooms should occur through management of $\mathrm{P}$ loading at local scales while ensuring lake-wide P concentrations do not increase.

The Consequences Question. How may we balance the interest in controlling nuisance growth of Cladophora in the nearshore through reduction of phosphorus discharges without exacerbating oligotrophication in the offshore to the detriment of the lower and upper food web?

1. The combined effect of reductions in external phosphorus loading to Lake Michigan and the benthification of paths of phosphorus recycling through mussel filtration of particulate phosphorus have driven offshore waters to a state of oligotrophy. This change has cascaded through the ecosystem, resulting in a reduction in prey species abundance and a decline in the number and condition of recreational and commercial fish species.

2. In the broadest sense, it is the point and nonpoint discharges of phosphorus received in the nearshore that provide the foundation for a food web that can support the desired fishery. However, as those discharges remain resident in the nearshore for a 
period of time before being delivered to the offshore by cross-margin transport, they provide phosphorus enrichment that can stimulate nuisance growth of Cladophora.

3. The conflicting nature of managing these two water-quality issues lies at the heart of what has been termed the Dual Challenge [18]. We refer to the two issues, Cladophora in the nearshore and the food web in the offshore, as endmembers for phosphorusmanagement scenarios. The phosphorus concentration required to eliminate nuisance Cladophora is the nearshore endmember and that supporting a healthy fishery is the offshore endmember. In this work, we applied a biophysical phosphorus-mussel model in establishing the nearshore endmember SRP concentration.

4. As illustrated by the map of nearshore SRP (Figure 13), reductions in total phosphorus manifested in the transition from the pre- to post-dreissenid period are driven by changes in the offshore PP concentration (SRP increased modestly). If one assumes that pre-dreissenid production in the offshore food web was sufficient to support the fishery, then it is the difference in PP offshore levels between the pre- and postdreissenid periods that must be "made up" in order to satisfy the objectives for the offshore endmember.

In conclusion, we used a biophysical model and an adopted criterion for nearshore SRP to support identification of combinations of SRP and PP in offshore waters that would meet the objective of the nearshore endmember, i.e., elimination of nuisance growth of Cladophora. We also provided a first-cut estimate for an allowable level of SRP and PP offshore, which could serve in achieving the offshore endmember objective (a healthy fishery) without sacrificing the nearshore endmember objective (elimination of nuisance algae growth). While the Dual Challenge may seem to represent an insurmountable obstacle, we have taken the first step by establishing the nearshore endmember. Future work with phosphorus-mussel-food web dynamics will necessarily focus on the offshore endmember. It will then be necessary to perform engineering analysis to identify discharge strategies, in time and place, for meeting the final endmember concentrations. We recommend that federal, state, and provincial authorities consider these findings in forming policies and establishing target phosphorus loads to address the Dual Challenge in the Great Lakes, reverse deterioration of nearshore water quality, and secure a healthy food web and fishery in the offshore.

Author Contributions: Conceptualization, M.T.A., P.X., and X.Z.; methodology, P.X., M.T.A., and X.Z.; software, X.Z.; validation, X.Z., M.T.A., and P.X.; formal analysis, X.Z., M.T.A., and P.X.; investigation, X.Z., M.T.A., and P.X.; writing-original draft preparation, P.X., M.T.A., and X.Z.; writing-review and editing, M.T.A., X.Z., and P.X; visualization, X.Z., M.T.A., and P.X.; supervision, P.X.; project administration, P.X.; funding acquisition, P.X. All authors have read and agreed to the published version of the manuscript.

Funding: This work Michigan Sea Grant College Program, Project Number Index R/CGLH-7, under award NA18OAR4170102 from National Sea Grant, NOAA, U.S. Department of Commerce, with funds from the State of Michigan.

Data Availability Statement: Data were extracted from the U.S. EPA Great Lakes Water Quality Survey GLENDA database on from https:/ / cdxnodengn.epa.gov/cdx-glenda (accessed on 5 April 2021).

Acknowledgments: This is the contribution 84 of the Great Lakes Research Center at Michigan Technological University. The Michigan Tech high performance computing cluster, Superior, was used in obtaining the hydrodynamic modeling results presented in this publication.

Conflicts of Interest: The authors declare no conflict of interest. 


\section{Appendix A. Study Sites on Lake Michigan}
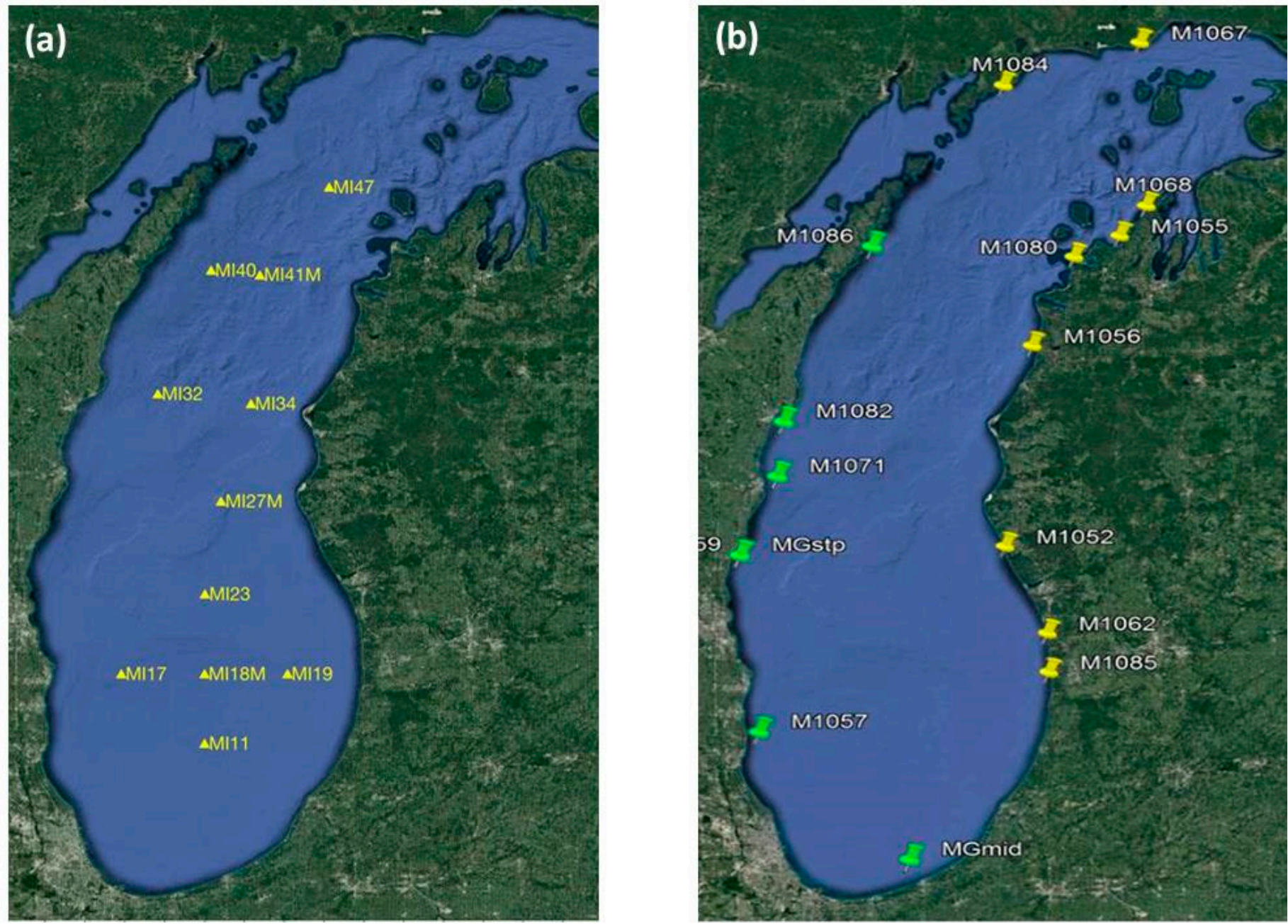

Figure A1. Sampling station locations: (a) offshore sites having a maximum depth $\geq 90 \mathrm{~m}$ and 30 or more years of record (U.S. EPA Great Lakes Water Quality Survey, GLENDA database) and (b) nearshore sites monitored by Yurista et al. [43].

Table A1. Site characteristics and rates of cross-margin flow for locations having differing coastal structure. With $Q$, cross-margin transport; $\tau$, water residence time; $\mathrm{H}$, average water depth; $\mathrm{A}_{\mathrm{cs}}$, transect cross-sectional area, $\mathrm{A}_{\mathrm{b}}$, bottom area; and $\mathrm{V}$, water volume.

\begin{tabular}{|c|c|c|c|c|c|c|}
\hline Site & $\begin{array}{c}Q \\
\left(10^{8} \mathrm{~m}^{3} \cdot \mathrm{d}^{-1}\right)\end{array}$ & $\begin{array}{c}\tau \\
\text { (d) }\end{array}$ & $\begin{array}{l}\mathrm{H} \\
(\mathrm{m})\end{array}$ & $\begin{array}{c}A_{\mathrm{cs}} \\
\left(10^{5} \mathrm{~m}^{2}\right)\end{array}$ & $\begin{array}{c}A_{b} \\
\left(10^{5} \mathrm{~m}^{2}\right)\end{array}$ & $\begin{array}{c}\mathrm{V} \\
\left(10^{9} \mathrm{~m}^{3}\right)\end{array}$ \\
\hline \multicolumn{7}{|l|}{ Embayments } \\
\hline Good Harbor Bay & 2.10 & 4.47 & 10 & 2.79 & 430 & 0.934 \\
\hline Big Bay De Noc & 2.19 & 15.3 & 7.63 & 2.51 & 4400 & 3.35 \\
\hline \multicolumn{7}{|l|}{ Nearshore Regions } \\
\hline Milwaukee, WI & 4.70 & 5.44 & 13.03 & 7.60 & 1965 & 2.56 \\
\hline $\begin{array}{c}\text { Southeast Lake } \\
\text { Michigan }\end{array}$ & 2.90 & 7.48 & 12.29 & 9.55 & 1770 & 2.17 \\
\hline
\end{tabular}



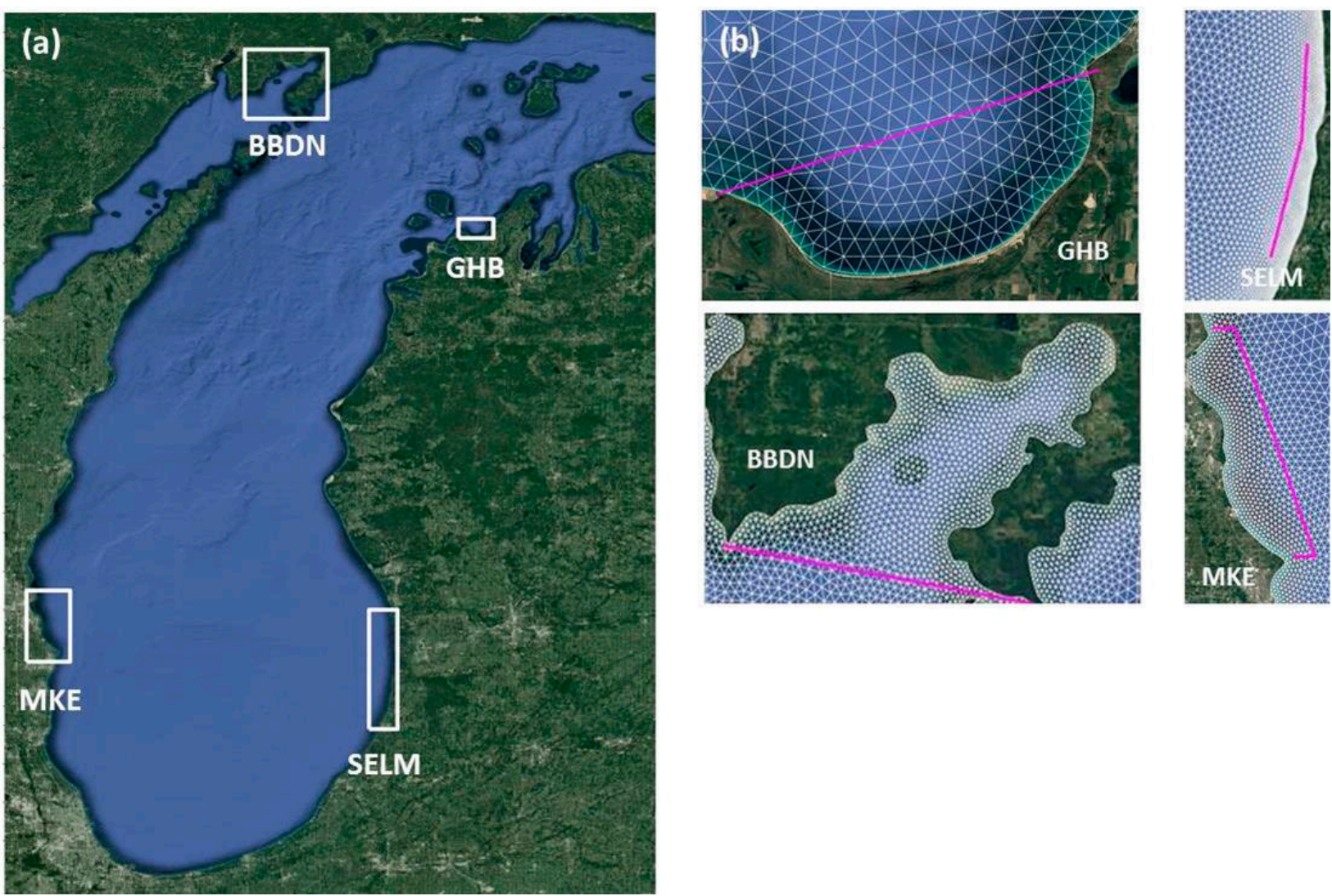

Figure A2. (a) Location of embayments (Good Harbor Bay, GHB and Big Bay de Noc, BBDN) and (b) near-linear shoreline segments (Southeast Lake Michigan, SELM and Milwaukee, MKE) used for comparison of cross-margin flow at sites having differing coastal structure.

\section{Appendix B. The Lake Michigan Phosphorus Environment}

Table A2. Determination of representative concentrations of total, particulate, dissolved organic, and soluble reactive phosphorus for the offshore waters of Lake Michigan.

(a) Spring cruise, surface water (Spring Surface) concentrations of total, particulate, dissolved organic, and soluble reactive phosphorus for offshore sites on Lake Michigan over the entire period of record, 1983-2018 ( $\mathrm{n}=940)$. Data extracted from the U.S. EPA Great Lakes Water Quality Survey GLENDA database prior to partitioning with respect to region (north south; east west) or era (pre- and post-dreissenid periods).

\begin{tabular}{cccc}
\hline & Mean $\left(\mathbf{m g P} \cdot \mathbf{m}^{-3}\right)$ & S.D. $\left(\mathbf{m g P} \cdot \mathbf{m}^{-3}\right)$ & Median $\left(\mathbf{m g P} \cdot \mathbf{m}^{-3}\right)$ \\
\hline TP & 4.17 & 1.44 & 4.03 \\
PP & 1.86 & 1.20 & 1.75 \\
DOP & 1.41 & 0.70 & 1.30 \\
SRP & 0.90 & 0.49 & 0.82
\end{tabular}

(b) Spring cruise, surface water (Spring Surface) concentrations of total, particulate, dissolved organic, and soluble reactive phosphorus for offshore sites on Lake Michigan, partitioned into data for the pre-dreissenid (1983-1992; $\mathrm{n}=339)$ and post-dreissenid (2009-2018; $\mathrm{n}=244)$ periods. Data extracted from the U.S. EPA Great Lakes Water Quality Survey GLENDA database.

\begin{tabular}{ccccccc}
\hline & & Mean $\left(\mathbf{m g P} \cdot \mathbf{m}^{-3}\right)$ & \multicolumn{2}{c}{ S.D. $\left(\mathbf{m g P} \cdot \mathbf{m}^{-\mathbf{3}}\right)$} & \multicolumn{2}{c}{ Median $\left(\mathbf{m g P} \cdot \mathbf{m}^{-3}\right)$} \\
\hline & Pre & Post & Pre & Post & Pre & Post \\
\hline TP & 5.02 & 3.06 & 1.56 & 0.76 & 4.80 & 3.03 \\
PP & 2.32 & 1.17 & 1.45 & 0.73 & 2.10 & 1.05 \\
DOP & 1.72 & 1.04 & 0.82 & 0.44 & 1.60 & 0.80 \\
SRP & 0.97 & 0.86 & 0.70 & 0.33 & & 0.84 \\
\hline
\end{tabular}


Table A2. Cont.

(c) Concentrations of total, soluble reactive, and particulate phosphorus for nearshore (depth $<20$ m) sites on Lake Michigan, partitioned into data for east (lower levels of watershed activity) and west (higher levels of watershed activity) stations. Data extracted from a monitoring survey performed in September 2010 by Yurista et al. [43] (Anne Cotter, U.S. EPA MED, personal communication).

\begin{tabular}{ccccccccc}
\hline & \multicolumn{3}{c}{ Nearshore East Stations } & \multicolumn{3}{c}{ Nearshore West Stations } \\
\hline & $\begin{array}{c}\text { Mean } \\
\left(\mathbf{m g P} \cdot \mathbf{m}^{-3}\right)\end{array}$ & $\begin{array}{c}\text { S.D. } \\
\left(\mathbf{m g P} \cdot \mathbf{m}^{-3}\right)\end{array}$ & $\mathbf{n}$ & $\begin{array}{c}\text { Median } \\
\left(\mathbf{m g P} \cdot \mathbf{m}^{-3}\right)\end{array}$ & $\begin{array}{c}\text { Mean } \\
\left(\mathbf{m g P}^{-3} \mathbf{m}^{-3}\right)\end{array}$ & $\begin{array}{c}\text { S.D. } \\
\left(\mathbf{m g P} \cdot \mathbf{m}^{-3}\right)\end{array}$ & $\mathbf{n}$ & $\begin{array}{c}\text { Median } \\
\left(\mathbf{m g P} \cdot \mathbf{m}^{-3}\right)\end{array}$ \\
\hline TP & 7.87 & 2.28 & 8 & 7.53 & 11.15 & 4.77 & 6 & 10.56 \\
PP & 6.11 & 1.28 & 8 & 5.70 & 6.39 & 1.09 & 4 & 6.12 \\
SRP & 1.54 & 0.38 & 9 & 1.45 & 2.27 & 0.50 & 6 \\
\hline
\end{tabular}

\section{References}

1. Higgins, S.N.; Malkin, S.Y.; Howell, E.T.; Guildford, S.J.; Campbell, L.; Hiriart-Baer, V.; Hecky, R.E. An ecological review of Cladophora glomerata (Chlorophyta) in the Laurentian Great Lakes. J. Phycol. 2008, 44, 839-854. [CrossRef]

2. Kuczynski, A.; Bakshi, A.; Auer, M.T.; Chapra, S.C. The canopy effect in filamentous algae: Improved modeling of Cladophora growth via a mechanistic representation of self-shading. Ecol. Model. 2020, 418, 108906. [CrossRef]

3. Kuczynski, A.; Auer, M.T.; Brooks, C.N.; Grimm, A.G. The Cladophora resurgence in Lake Ontario: Characterization and implications for management. Can. J. Fish. Aquat. Sci. 2016, 73, 999-1013. [CrossRef]

4. Chun, C.L.; Ochsner, U.; Byappanahalli, M.N.; Whitman, R.L.; Tepp, W.H.; Lin, G.; Johnson, E.A.; Peller, J.; Sadowsky, M.J. Association of toxin-producing Clostridium botulinum with the macroalga Cladophora in the Great Lakes. Environ. Sci. Technol. 2013, 47, 2587-2594. [CrossRef] [PubMed]

5. Ishii, S.; Yan, T.; Shively, D.A.; Byappanahalli, M.N.; Whitman, R.L.; Sadowsky, M.J. Cladophora (Chlorophyta) spp. harbor human bacterial pathogens in nearshore water of Lake Michigan. Appl. Environ. Microbiol. 2006, 72, 4545-4553. [CrossRef] [PubMed]

6. Auer, M.T.; Canale, R.P. Ecological studies and mathematical modeling of Cladophora in Lake Huron: 2. Phosphorus uptake kinetics. J. Gt. Lakes Res. 1982, 8, 84-92. [CrossRef]

7. Higgins, S.N.; Pennuto, C.M.; Howell, E.T.; Lewis, T.W.; Makarewicz, J.C. Urban influences on Cladophora blooms in Lake Ontario. J. Gt. Lakes Res. 2012, 38, 116-123. [CrossRef]

8. Hecky, R.E.; Smith, R.E.; Barton, D.R.; Guildford, S.J.; Taylor, W.D.; Charlton, M.N.; Howell, T. The nearshore phosphorus shunt: A consequence of ecosystem engineering by dreissenids in the Laurentian Great Lakes. Can. J. Fish. Aquat. Sci. 2004, 61, 1285-1293. [CrossRef]

9. Dove, A.; Chapra, S.C. Long-term trends of nutrients and trophic response variables for the Great Lakes. Limnol. Oceanogr. 2015, 60, 696-721. [CrossRef]

10. Painter, D.S.; Kamaitis, G. Reduction of Cladophora biomass and tissue phosphorus in Lake Ontario 1972-83. Can. J. Fish. Aquat. Sci. 1987, 44, 2212-2215. [CrossRef]

11. Bootsma, H.A.; Rowe, M.D.; Brooks, C.N.; Vanderploeg, H.A. Commentary: The need for model development related to Cladophora and nutrient management in Lake Michigan. J. Gt. Lakes Res. 2015, 41, 7-15. [CrossRef]

12. Auer, M.T.; McDonald, C.P.; Kuczynski, A.; Huang, C.; Xue, P. Management of the phosphorus-Cladophora dynamic at a site on lake ontario using a multi-module bioavailable P model. Water 2021, 13, 375. [CrossRef]

13. Lambert, R.S.; Auer, M.T.; Effler, S.W.; Greene, M.R.; Downer, B.E.; Kuczynski, A. Onondaga to Ontario: Management of bioavailable phosphorus in municipal wastewaters for control of Cladophora. J. Gt. Lakes Res. 2015, 41, 1106-1113. [CrossRef]

14. Bootsma, H.A.; Young, E.B.; Berges, J.A. Water quality management options to control Cladophora growth in the Milwaukee region of Lake Michigan. In Final Report for the Milwaukee Metropolitan Sewerage District; Univercity Wisconsin-Milwaukee: Milwaukee, WI, USA, 2008.

15. Bootsma, H.A.; Waples, J.T.; Liao, Q. Identifying major phosphorus pathways in the Lake Michigan nearshore zone. In MMSD Contract M03029P05; Milwaukee Metropolitan Sewerage District: Milwaukee, WI, USA, 2012.

16. Howell, E.T. Cladophora (green algae) and dreissenid mussels over a nutrient loading gradient on the north shore of Lake Ontario. J. Gt. Lakes Res. 2018, 44, 86-104. [CrossRef]

17. Shen, C.; Liao, Q.; Bootsma, H.A. Modelling the influence of invasive mussels on phosphorus cycling in Lake Michigan. Ecol. Model. 2020, 416, 108920. [CrossRef]

18. Hecky, R.E.; DePinto, J.V. Understanding Declining Productivity in the Offshore Regions of the Great Lakes; International Joint Commission: Windsor, ON, Canada, 2020; p. 62.

19. Bravo, H.R.; Bootsma, H.; Khazaei, B. Fate of phosphorus from a point source in the Lake Michigan nearshore zone. J. Gt. Lakes Res. 2019, 45, 1182-1196. [CrossRef]

20. Ozersky, T.; Malkin, S.Y.; Barton, D.R.; Hecky, R.E. Dreissenid phosphorus excretion can sustain C. glomerata growth along a portion of Lake Ontario shoreline. J. Gt. Lakes Res. 2009, 35, 321-328. [CrossRef] 
21. Dayton, A.I.; Auer, M.T.; Atkinson, J.F. Cladophora, mass transport, and the nearshore phosphorus shunt. J. Gt. Lakes Res. 2014, 40, 790-799. [CrossRef]

22. Bootsma, H.A. Causes, consequences and management of nuisance Cladophora. In US Enviromental Protection Agency Project GL-00E06901; Great Lakes National Program Office: Chicago, IL, USA, 2009.

23. Przybyla-Kelly, K.; Nevers, M.B.; Shively, D.A.; Benson, S.P.; Carter, G.M.; Dwyer, S.C.; Lewan, M.E.; Picard, K.R.; Richards, L.C.; Sopovski, D.S.; et al. Cladophora Biomass and Supporting Data Collected in the Great Lakes 2019; U.S. Geological Survey: Reston, VA, USA, 2019. [CrossRef]

24. Nalepa, T.F.; Fanslow, D.L.; Lang, G.A.; Mabrey, K.; Rowe, M. Lake-Wide Benthic Surveys in Lake Michigan in 1994-95, 2000, 2005, and 2010: Abundances of the Amphipod Diporeia spp. and Abundances and Biomass of the Mussels Dreissena Polymorpha and Dreissena Rostriformis Bugensis; NOAA Technical MemorandumGLERL-164; NOAA, Great Lakes Environmental Research Laboratory: AnnArbor, MI, USA, 2014.

25. Limno, T. Good Harbor Bay Dreissenid Mussel Control Demonstration Project Final Project Report; Great Lakes Commission and Invasive Mussel Collaborative Partners: Ann Arbor, MI, USA, 2020; p. 70.

26. Nalepa, T.F.; Cavaletto, J.F.; Ford, M.; Gordon, W.M.; Wimmer, M. Seasonal and annual variation in weight and biochemical content of the zebra mussel, Dreissena polymorpha, in Lake St. Clair. J. Gt. Lakes Res. 1993, 19, 541-552. [CrossRef]

27. Glyshaw, P.W.; Riseng, C.M.; Nalepa, T.F.; Pothoven, S.A. Temporal trends in condition and reproduction of quagga mussels (Dreissena rostriformis bugensis) in southern Lake Michigan. J. Gt. Lakes Res. 2015, 41, 16-26. [CrossRef]

28. Li, J.; Ianaiev, V.; Huff, A.; Zalusky, J.; Ozersky, T.; Katsev, S. Benthic invaders control the phosphorus cycle in the world's largest freshwater ecosystem. Proc. Natl. Acad. Sci. USA 2021, 118, e2008223118. [CrossRef] [PubMed]

29. Rowe, M.D.; Anderson, E.J.; Vanderploeg, H.A.; Pothoven, S.A.; Elgin, A.K.; Wang, J.; Yousef, F. Influence of invasive quagga mussels, phosphorus loads, and climate on spatial and temporal patterns of productivity in Lake Michigan: A biophysical modeling study. Limnol. Oceanogr. 2017, 62, 2629-2649. [CrossRef]

30. Bierman, V.J., Jr.; Kaur, J.; DePinto, J.V.; Feist, T.J.; Dilks, D.W. Modeling the role of zebra mussels in the proliferation of blue-green algae in Saginaw Bay, Lake Huron. J. Gt. Lakes Res. 2005, 31, 32-55. [CrossRef]

31. James, W.F.; Barko, J.W.; Davis, M.; Eakin, H.L.; Rogala, J.T.; Miller, A.C. Filtration and excretion by zebra mussels: Implications for water quality impacts in Lake Pepin, upper Mississippi River. J. Freshw. Ecol. 2000, 15, 429-437. [CrossRef]

32. Turner, C.B. Influence of zebra (Dreissena polymorpha) and quagga (Dreissena rostriformis) mussel invasions on benthic nutrient and oxygen dynamics. Can. J. Fish. Aquat. Sci. 2010, 67, 1899-1908. [CrossRef]

33. Mosley, C.; Bootsma, H. Phosphorus recycling by profunda quagga mussels (Dreissena rostriformis bugensis) in Lake Michigan. J. Gt. Lakes Res. 2015, 41, 38-48. [CrossRef]

34. Vanderploeg, H.A.; Liebig, J.R.; Nalepa, T.F.; Fahnenstiel, G.L.; Pothoven, S.A. Dreissena and the disappearance of the spring phytoplankton bloom in Lake Michigan. J. Gt. Lakes Res. 2010, 36, 50-59. [CrossRef]

35. Fanslow, D.L.; Nalepa, T.F.; Lang, G.A. Filtration rates of the zebra mussel (Dreissena polymorpha) on natural seston from Saginaw Bay, Lake Huron. J. Gt. Lakes Res. 1995, 21, 489-500. [CrossRef]

36. Baldwin, B.S.; Mayer, M.S.; Dayton, J.; Pau, N.; Mendilla, J.; Sullivan, M.; Moore, A.; Ma, A.; Mills, E.L. Comparative growth and feeding in zebra and quagga mussels (Dreissena polymorpha and Dreissena bugensis): Implications for North American lakes. Can. J. Fish. Aquat. Sci. 2002, 59, 680-694. [CrossRef]

37. Lei, J.; Payne, B.S.; Wang, S.Y. Filtration dynamics of the zebra mussel, Dreissena polymorpha. Can. J. Fish. Aquat. Sci. 1996, 53, 29-37. [CrossRef]

38. Marescaux, J.; von Oheimb, K.C.; Etoundi, E.; von Oheimb, P.V.; Albrecht, C.; Wilke, T.; Van Doninck, K. Unravelling the invasion pathways of the quagga mussel (Dreissena rostriformis) into Western Europe. Biol. Invasions 2016, 18, 245-264. [CrossRef]

39. Diggins, T.P. A seasonal comparison of suspended sediment filtration by quagga (Dreissena bugensis) and zebra (D. polymorpha) mussels. J. Gt. Lakes Res. 2001, 27, 457-466. [CrossRef]

40. Xia, Z.; MacIsaac, H.J.; Hecky, R.E.; Depew, D.C.; Haffner, G.D.; Weidman, R.P. Multiple factors regulate filtration by invasive mussels: Implications for whole-lake ecosystems. Sci. Total Environ. 2021, 765, 144435. [CrossRef] [PubMed]

41. Stoeckmann, A.M.; Garton, D.W. A seasonal energy budget for zebra mussels (Dreissena polymorpha) in western Lake Erie. Can. J. Fish. Aquat. Sci. 1997, 54, 2743-2751. [CrossRef]

42. Pothoven, S.A.; Fahnenstiel, G.L. Recent change in summer chlorophyll a dynamics of southeastern Lake Michigan. J. Gt. Lakes Res. 2013, 39, 287-294. [CrossRef]

43. Yurista, P.M.; Kelly, J.R.; Cotter, A.M.; Miller, S.E.; Van Alstine, J.D. Lake Michigan: Nearshore variability and a nearshore-offshore distinction in water quality. J. Gt. Lakes Res. 2015, 41, 111-122. [CrossRef]

44. Huang, C.; Kuczynski, A.; Auer, M.T.; O’Donnell, D.M.; Xue, P. Management transition to the Great Lakes nearshore: Insights from hydrodynamic modeling. J. Mar. Sci. Eng. 2019, 7, 129. [CrossRef]

45. Kelley, J.G.W.; Chen, Y.; Anderson, E.J.; Lang, G.A.; Peng, M. Upgrade of NOS Lake Michigan and Lake Huron Operational Forecast Systems to FVCOM: Model Development and Hindcast Skill Assessment; NOAA Technical Memorandum NOS CS, 42; National Ocean Service Coast Survey Development Laboratory: Silver Spring, MD, USA, 2020.

46. Benjamin, S.G.; Weygandt, S.S.; Brown, J.M.; Hu, M.; Alexander, C.R.; Smirnova, T.G.; Olson, J.B.; James, E.P.; Dowell, D.C.; Grell, G.A.; et al. A North American hourly assimilation and model forecast cycle: The rapid refresh. Mon. Weather Rev. 2016, 144, 1669-1694. [CrossRef] 
47. Peng, M.; Zhang, A.; Anderson, E.J.; Lang, G.A.; Kelley, J.G.W.; Chen, Y. Implementation of the Lakes Michigan and Huron Operational Forecast System (LMHOFS) and the Nowcast/Forecast Skill Assessment; NOAA Technical Report NOS CO-OPS, 091; National Ocean Service Center for Operational Oceangraphic Products and Services: Silver Spring, MD, USA, 2019.

48. Auer, M.T.; Canale, R.P. Ecological studies and mathematical modeling of Cladophora in Lake Huron: 3 . The dependence of growth rates on internal phosphorus pool size. J. Gt. Lakes Res. 1982, 8, 93-99. [CrossRef]

49. Tomlinson, L.M.; Auer, M.T.; Bootsma, H.A.; Owens, E.M. The Great Lakes Cladophora model: Development, testing, and application to Lake Michigan. J. Gt. Lakes Res. 2010, 36, 287-297. [CrossRef]

50. Kuczynski, A.; Auer, M.T.; Taylor, W.D.; Chapra, S.C. Keeping up with the math: Advancing the ecological foundation of the Great Lakes Cladophora Model. Ecol. Model. In Review.

51. Waples, J.T.; Klump, J.V. Vertical and horizontal particle transport in the coastal waters of a large lake: An assessment by sediment trap and thorium-234 measurements. J. Geophys. Res. Ocean. 2013, 118, 5376-5397. [CrossRef]

52. Waples, J.T.; Bootsma, H.A.; Klump, J.V. How are coastal benthos fed? Limnol. Oceanogr. Lett. 2017, 2, 18-28. [CrossRef]

53. Xue, P.; Schwab, D.J.; Hu, S. An investigation of the thermal response to meteorological forcing in a hydrodynamic model of Lake Superior. J. Geophys. Res. Ocean. 2015, 120, 5233-5253. [CrossRef]

54. Xue, P.; Pal, J.S.; Ye, X.; Lenters, J.D.; Huang, C.; Chu, P.Y. Improving the simulation of large lakes in regional climate modeling: Two-way lake-atmosphere coupling with a 3D hydrodynamic model of the Great Lakes. J. Clim. 2017, 30, 1605-1627. [CrossRef]

55. Ye, X.; Anderson, E.J.; Chu, P.Y.; Huang, C.; Xue, P. Impact of water mixing and ice formation on the warming of Lake Superior: A model-guided mechanism study. Limnol. Oceanogr. 2019, 64, 558-574. [CrossRef]

56. Ye, X.; Chu, P.Y.; Anderson, E.J.; Huang, C.; Lang, G.A.; Xue, P. Improved thermal structure simulation and optimized sampling strategy for Lake Erie using a data assimilative model. J. Gt. Lakes Res. 2020, 46, 144-158. [CrossRef] 